\section{Ankara Üniversitesi Eğitim Bilimleri Fakültesi Özel Eğitim Dergisi}

2022, 23(1), 165-189
DERLEME

Gönderim Tarihi: 18.05.20

Kabul Tarihi: 27.01.21

Erken Görünüm: 31.01.21

\title{
İşitme Kaybı Olan Çocuklarda Yürütücü İşlevler Araştırmaları Üzerine Bir Sistematik Derleme*
}

\author{
Emel Ertürk-Mustul ${ }^{\text {D } 1}$
}

\author{
Murat Doğan iD2
}

Öz

Giriş: İşitme kaybı olan (IK) çocukların dil gelişimini anlama çabasına son yıllarda bilişsel gelişimi anlama çalışmaları da eklenmiştir. Bu araştırmada temel bilişsel süreçlerden biri olan yürütücü işlevlere odaklanmış araştırmaları derleyerek İK çocuklarda yürütücü işlevlerin diğer bilişsel süreçlerle/becerilerle ilişkisi ve bu çocukların yürütücü işlevler performansı üzerine genel bir bakış açısı ortaya koymak amaçlanmıştır.

Yöntem: Sistematik derleme metodolojisi ile belirlenen dâhil etme ve dışlama ölçütleri doğrultusunda 15 araştırma derleme kapsamına alınmıştır.

Bulgular: Bulgular (a) yürütücü işlevler ile dil arasında karşılıklılık ilişkisi olduğuna, (b) İK çocukların yürütücü işlevler performansının işiten akranlarına göre daha zayıf olduğuna, (c) yürütücü işlevler performansında koklear implantlı ile işitme cihazlı çocuklar arasında ve anadili işaret dili olanlar ile işiten çocuklar arasında farklılık olmadığına, (d) kaynaştırma ortamındaki koklear implantlı çocukların işitme engelliler okulundakilere göre yürütücü işlevlerde daha başarılı olduklarına ve (e) erken eğitim programlarında bilişsel süreçlerin dil ile dengeli biçimde desteklenmesi gerektiğine işaret etmektedir.

Tartışma: İK çocukların yürütücü işlevler performansının işiten akranlarını geriden takip etmesi diğer bilişsel süreçleri inceleyen bazı araştırma bulgularıyla tutarlılık göstermektedir. Yürütücü işlevler ile diğer bilişsel süreçler/beceriler arasında ilişkiye dair bir yargıya varılamadığı, yürütücü işlevler ile dil arasındaki ilişkinin nedensellikten çok karş1lıklılık içinde olduğu söylenebilir.

Sonuç ve Öneriler: Bulgular daha fazla araştırmaya ihtiyaç olduğunu göstermekte, yeni araştırmaların da erken eğitim programlarına katkı sağlayacağına inanılmaktadır. Dil gelişimi-bilişsel gelişim dengesinin gözetildiği erken eğitim programlarının İK çocuklar ile işiten akranları arasındaki yürütücü işlevler performans farkının en aza indirilmesinde etkili olabileceği ileri sürülebilir.

Anahtar sözcükler: İşitme kaybı olan çocuklar, koklear implant, bilişsel süreçler/beceriler, yürütücü işlevler, erken eğitim programları.

Atıf için: Ertürk-Mustul, E., \& Doğan, M. (2022). İşitme kaybı olan çocuklarda yürütücü işlevler araştırmaları üzerine bir sistematik derleme. Ankara Üniversitesi Ĕgitim Bilimleri Fakültesi Özel Eğitim Dergisi, 23(1), 165-189. https://doi.org/10.21565/ozelegitimdergisi.739073

\footnotetext{
*Bu araştırma 2-5 Mayıs 2018 tarihlerinde Antalya'da düzenlenen V. Uluslararası Avrasya Eğitim Araştırmaları Kongresi'nde sözlü bildiri olarak sunulmuştur.

${ }^{1}$ Sorumlu Yazar: Arş. Gör., Anadolu Üniversitesi, E-posta: emelerturk@ anadolu.edu.tr, https://orcid.org/0000-0001-6641$\underline{6146}$

$\frac{61}{2 D o c ̧ . ~ D r ., ~ A n a d o l u ~ U ̈ n i v e r s i t e s i, ~ E-p o s t a: ~ m u r a t p s y c h o @ g m a i l . c o m, ~ h t t p s: / / o r c i d . o r g / 0000-0003-4942-3760 ~}$
} 


\section{Giriş}

İşitme kaybı olan (IKK) çocuklarda bilişsel süreçlere olan akademik ilgi çeşitli nedenlerle yıllar içinde belirgin bir artış göstermiștir. Bu nedenlerin başında İK çocukların dil becerilerini etkileyen bilişsel faktörlerin (Clark, 2001; Marschark, 2001) ve bilişsel özellikleri ile akademik performansları arasındaki ilişkinin (Braden, 2001) belirlenmek istenmesi gelmektedir. İK çocuklar için tanı sonrası yapılacak müdahalelere ve yerleştirilecekleri eğitim ortamlarına karar vermede bilişsel değerlendirme sonuçlarına da ihtiyaç duyulmaktadır (Edwards \& Crocker, 2008). 2000’li yılların başında İK çocuklarla yapılan çalışmalarda uygulamalı araştırmalar ile temel araştırmaların birleştirilmesine ilişkin yeni bir bakışın ortaya çıkması biliş çalışmalarının ivmesini artırmıştır (Clark, 2001; Marschark, 2001).

IK çocuklarda bilişsel süreçlerle ilgili çalışmalar arasında en çok zekâ konusuna odaklanan araştırmalara rastlanmaktadır (Ör., Barbosa vd., 2013; Phillips vd., 2014). Zekâ araştırmalarının ortak bulguları, İK çocukların zekâ düzeylerinin işiten akranlarından farklı olmadığı, ancak zekânın işleyişinde nitel farklılıklar olabileceği yönündedir. Örneğin, İK çocuklar mizah duygusu, mecaz kullanımı gibi soyut düşünme gerektiren becerilerde yaşıtlarından farklılık gösterebilmektedirler (Maller, 2003). Günümüzde İK çocuklar ile işiten çocuklar arasında zihinsel süreçlerin nitel boyutundaki olası farklılıkların bir eksiklik olmadığı kabul görmektedir (Barbosa vd., 2013; Marschark, 2003, 2006; Phillips vd., 2014).

IK çocuklarda zekâdan sonra en çok araştırılan bilişsel süreç bellektir (Cleary vd., 2001; Marschark \& Hauser, 2008). Bu yönde 1950 ile 1970 yılları arasındaki araştırmalar İK çocukların işiten akranlarına göre bellek performansında geri kaldıklarını rapor etmektedir (Furth \& Pufall, 1966; Ling, 1975; Marschark \& Mayer, 1998). 1980-1990 arasındaki araştırmalarda işaret dili kullanan İK bireylere odaklanma eğilimi görülmektedir (Hanson, 1990; Shand, 1982). 1990-2000 arası araştırmalarda İK çocuklar ve işiten çocuklar arasında bellek performansı için gerekli olan işleme süreçlerinde farkll1ıklar olduğu belirtilmektedir (Jutras \& Gagné, 1999; Marschark \& Mayer, 1998; Todman \& Seedhouse, 1994). Doğan ve Hasanoğlu'nun (2016) yaptıkları araştırma yakın geçmişte yapılan bellekle ilgili araştırmaların bulgularına ilişkin önemli bilgiler sağlamaktadır. Bu araştırmada 2000-2015 yılları arasında bellek ve bellekle ilişkili süreçlere odaklanan araştırmalara içerik analizi yaparak 25 uluslararası araştırmanın yöntem ve konu eğilimlerini belirlemişlerdir. Buna göre, yöntemsel olarak üç eğilim görülmüsstür: (a) İK çocukların, bellek kapasitesi ve bellekle ilişkili becerilerini belirlemek için işiten çocukların norm grubu olarak kabul edildiği, (b) katılımcılar arasındaki bireysel farklılıklara göre değerlendirmeler yapıldığı, (c) araştırmaların büyük bir kısmının nedensel-karşılaştırmalı ve korelasyonel araştırma ile desenlendiği görülmüştür. Konu odaklı olarak da dört eğilim görülmüştür: (a) Bellek konusunun daha çok koklear implantlı çocuklarla çalışıldığı ve bu çocukların büyük çoğunluğunun iletişim yönteminin sözel olduğu, (b) bellek, dil ve okuma-yazma arasında olumlu bir ilişkinin olduğu, (c) araştırmaların büyük bir kısmında katılımcıların eğitim ortamlarının kaynaştırma sınıfları olduğu ve (d) araştırmaların neredeyse hepsinde kısa süreli bellek ve çalışma belleğinin çalışıldığı sonucuna ulaşılmıştır. Ayrıca karşılaştırmalı olarak yapılan 15 araştırmanın onunda işiten çocuklar daha yüksek bellek performansı gösterirken, beşinde İK çocukların bellek kapasitesinin daha iyi olduğuna ulaşılması dikkat çeken başka bulgulardır.

Son yıllarda yenidoğan işitme taramalarında, işitme teknolojilerinde ve erken eğitim programlarında çok önemli gelişmeler meydana gelmiştir (Estabrooks vd., 2016). Özellikle işitsel-sözel temelli erken eğitim programlarının işlerliğinin artmasıyla birlikte İK çocuklarda dil gelişimini etkileyen bilişsel faktörler eskisinden daha çok araştırılmaya başlanmıştır. Bu geliş̧elerin sonucunda yürütücü işlevler de kaçınılmaz olarak İK çocukların değerlendirildiği araştırmaların odağına oturmuş̧ur (Ör., Figueras vd., 2008; Woolfe vd., 2002).

\section{Yürütücü İşlevlerin Tanımı ve Kapsamı}

Yürütücü işlevlerin erken yaşlarda başladığı, uzun süreli bir gelişim dönemine yayıldığı ve erken yetişkinlik döneminde nörolojik gelişime paralel bir şekilde sürekli devam ettiği anlaşılmaktadır (Beer vd., 2014; Beer vd., 2010; Hughes vd., 2004). Yürütücü işlevler bir işi planlama, plana/amaca yönelik davranışları organize etme, organize edildiği biçimde davranışları başlatma, devam ettirme ve sonlandırma becerilerinin tamamını içeren bir bilişsel süreçtir (Beer vd. 2014; Beer vd., 2010; Hall vd., 2017). Şemsiye terim olan yürütücü işlevlerin, farklı bileşenlerinin olduğu görülmektedir. En çok bilinen alt bileşenleri bilişsel esneklik, öz düzenleme, planlama, çalışma belleği ve ketleme kontrolüdür. Bunlar dışında yürütücü işlevler şemsiye teriminin altında sözlü ve sözsüz çalışma belleği, dikkat, duygusal ve davranışsal düzenleme, öz denetim, uyarıcıları düzenleme, düşünme, organize etme, problem çözme, karar verme ve konuşma akıcılı̆̆ gibi bileşenlerin de olduğu görülmektedir. Bir başka deyişle yürütücü işlevlerin gerçekleşmesi için bu alt bileşenler gibi bilişsel süreçler gereklidir (Beer vd., 2014; Beer vd., 2010; Hughes vd., 2004). 
Yürütücü işlevler aynı zamanda bilişsel becerileri, davranış ve duyguları organize etmeyi ve yönlendirmeyi sağlayan bir sistem olarak da düşünülebilir (Beer vd. 2014; Beer vd., 2010; Hughes vd., 2004). Tipik gelişim gösteren bebek ve küçük çocukların uygun olmayan birçok baskın uyarıcı ile dikkatlerinin dağıldığı görülür. Buradaki uygun olmayan ile anlatılmak istenen çocuğun o an üzerinde durduğu ya da planladığı işle ilişkili olmayan uyarıcılardır (Hughes vd., 2004; Santrock, 2011). İzleyen örnek, yürütücü işlevlerin gelişimi ve kavramın ne olduğunun daha açık anlaşılması için önemlidir. Bir anne 11 aylık bebeğini elinde biberonla mutfağın kapısından çağııır. Biberona doğru emekleyerek giderken kenarda duran kırmızı eşarp (baskın uyarıcı) bebeğin ilgisini çeker. Bebek biberona doğru gitmek yerine durup kırmızı eşarp ile meşgul olmaya başlar. Kırmızı eşarp çocuğun dikkatini çeker ve çocuğun davranışını kendisine yönlendirir. Bebeğin asıl planı böylece başka bir uyarıcı ile bölünmüş ve yeni bir plan söz konusu olmaya başlamıştır. Bunun sebebi yürütücü işlevlerin henüz gelişmemiş olmasıdır. Erken çocukluk çağında çocuklar, amaçları ile ilişkili olmayan uyarıcılara ket vurma becerisini geliştirdikçe davranışları daha az kesintiye uğrayarak, artan bir şekilde stratejik ve planlı olmaya başlarlar (Hughes vd., 2004). Çocuklar bu aşamalardan geçerken yetişkinler, kurdukları etkileşimler bağlamında çocukların doğuştan getirdikleri becerileri sürekli desteklemektedirler (Bernier vd., 2010; Bodrova \& Leong, 1996, 2013; Carlson, 2003). Böylece yürütücü işlevler gelişme gösterdikçe çocukların yeni becerileri öğrenme ve geliştirme yetenekleri artar, başladıkları iş başında kalma süreleri de uzar. Düşüncelerini ve davranışlarını organize etmede daha esnek ve yetenekli hale gelen çocukların daha karmaşık planlama, organize etme ve karar verme süreçlerinin üstesinden gelme becerileri zamanla gelişir (Hughes vd., 2004). Yukarıdaki örneği çeşitlendirmek mümkündür. Okul çağında bir çocuk için sınıfta dersi dikkatli dinleyebilme, ödevlerini başlayıp bitirme, bir proje ödevi planlama ve planlanan şekilde uygulama, yetişkinlik çağında bir birey için stresli durumlarla başa çıkabilme, sağlıksız yiyeceklere karşı durabilme gibi beceriler yürütücü işlevler için günlük yaşam içinden verilebilecek örneklerdir (Norman \& Shallice, 1986).

\section{İK Çocuklarda Yürütücü İşlevler}

Erken yaşlarda ortaya çıkan işitsel yoksunluğun yürütücü işlevleri olumsuz etkilediği belirtilmektedir (Geers vd., 2003). Hall ve diğerleri (2017) ise, araştırmaları sonucunda İK çocukların yürütücü işlevler performansında güçlük yaşamalarının tek nedeninin işitsel yoksunluk olmadığını, buna bağlı erken yaşlarda dil yoksunluğunun da önemli bir neden olduğunu ileri sürmektedirler. Bununla birlikte alanyazında da yürütücü işlevler ile dil arasında karşılıklı etki tepki sonucu gelişen bir ilişki olduğu varsayılmaktadır (Beer vd., 2014). Bu varsayımın temeli, yürütücü işlevlerin öz düzenleme, sözel aracıllk, çalışma belleği, ardlşılk işleme stratejileri ve işlerin gerçekleşmesinde kullanılan araçlar ve deneyimleri (dil, fonolojik farkındalık gibi) sağladığı için konuşma becerilerinin gelişiminde etkili olduğu düşüncesine dayanmaktadır. Dolayısıyla yürütücü işlevlerin dil ile yakından ilişkili olduğu ve dil gelişimi konusunda etkili bir role sahip olduğu ileri sürülmektedir (Beer vd., 2011; Kronenberger vd., 2013). İK çocuklarda yürütücü işlevleri inceleyen araştırmalarda çoğunlukla koklear implantlı çocukların ele alındığı görülmektedir (Ör., AuBuchon vd., 2015; Beer vd., 2014). Koklear implantlı çocuklar konuşma algılama, kelime tanıma ve dil becerileri konusunda gelişim gösterseler de dil performanslarında niteliksel farklılıklar olmaktadır (Surowiecki vd., 2002). Dahası koklear implantlı çocuklar bu teknolojiye rağmen konuşma algılama ve sözlü dil konusunda akranlarından geri kalabilmektedirler. Bu konuyla ilgili olarak "Bazı koklear implantl çocuklar konuşma algılama ve sözlü dil gelişiminde işiten akranlarına yetişirken bazıları neden işiten akranlarına göre çok geri kalmaktadırlar?" sorusu akla gelmektedir. Koklear implant ameliyatı sonrasında bireysel farklılıklar, aile katılımı, erken eğitim, iletişim yöntemi vb. değişkenler çocuğun gelişimini etkileyen faktörlerdir. Fakat yine de bu değişkenler koklear implantlı çocuklar arasındaki farklılıkları açıklama konusunda yeterli bulunmamaktadır (Pisoni vd., 2008). Bununla birlikte alanyazında bu tip değişkenlerin ortaya konulmasında ilerleme kaydedilmesine karşın bilişsel süreçlerin dil ve konuşma performansı üzerindeki rolü üzerine çok az ilerleme kaydedildiği belirtilmektedir (Pisoni \& Cleary, 2004). Bilişsel süreçlerden her birinin rolünün ayrı ayrı bilinmesi ile koklear implantlı çocuklardan bazılarının işiten akranlarına göre neden geri kaldıkları sorusuna yanıt bulunabileceği ileri sürülmektedir (Pisoni vd., 2008; Pisoni \& Cleary, 2004). Bu bağlamda İK çocuklarda yürütücü işlevler üzerine uluslarası düzeyde sınırlı sayıda araştırma bulunurken (Ör., Figueras vd., 2008; Surowiecki vd., 2002) ulusal alanyazında da yalnızca bir araştırma bulunmaktadır (Şipal \& Bayhan, 2010). Bu nedenle yürütücü işlevler ile, başta dil olmak üzere, diğer bilişsel süreçler/beceriler arasındaki ilişkiye dair alanyazındaki bulguların sistematik biçimde derlenerek bir senteze ulaşılmasının alanyazına katkı sağlayacağı düşünülmektedir. Elde edilen bulguların araştırmacılara ve alanda çalışan uygulamacılara eğitim programlarını planlamaları açısından yol gösterici olacağına inanılmaktadır.

İK çocuklarda yürütücü işlevler ile dil arasında ilişki olduğu varsayımı ve koklear implantlı çocukların kendi aralarında gelişimsel farklılıkların bulunmasına ilişkin soru ile birlikte yürütücü işlevler ile diğer bilişsel süreçler/beceriler ilişkisinin bilinmesine duyulan gereksinim bu araştırmanın gerekçelerini oluşturmaktadır. $\mathrm{Bu}$ 
araştırmada temel bilişsel süreçlerden biri olan yürütücü işlevlere odaklanmış araştırmaları derleyerek İK çocuklarda yürütücü işlevlerin diğer bilişsel süreçlerle/becerilerle ilişkisi ve bu çocukların yürütücü işlevler performansı üzerine genel bir bakış açısı ortaya koymak amaçlanmıştır. Bu amaç doğrultusunda şu sorulara yanıt aranmıştır:

1. Araştırmaların yöntemsel özellikleri (katılımcı özellikleri, araştırma desenleri, ölçme araçları) nelerdir?

2. Araştırmaların ana bulguları nelerdir?

3. Araştırmaların eğitim uygulamaları için önerileri nelerdir?

\section{Yöntem}

Bu araştırmada sistematik derleme metodolojisi benimsenmiştir. Sistematik derleme, belli bir alan içinde yayınlanmış tüm çalışmaların yine alan uzmanları tarafından kapsamlı bir şekilde taranarak bir araştırma kanııına götüren sentez çalışmasıdır. Taramalar sonucunda belirlenen dâhil etme ve dışlama ölçütleriyle birlikte hangi araştırmaların dâhil edileceği belirlenerek derlemeye alınan araştırma bulgularının sistematik ve kapsamlı bir şekilde sentezlenmesiyle yürütülmektedir (Grove vd., 2015; Karaçam, 2013).

\section{Tarama Stratejisi}

Bu derlemede yapılan taramalara yıllar açısından herhangi bir sınırlama getirilmemiştir. Ebscohost, Eric, Google Schoolar, OECD iLibrary, Sage, ScienceDirect, SpringerLink, Scopus, Taylor \& Francis ve Web of Science veri tabanlarında Türkçe ve İngilizce dillerinde "yürütücü işlevler", "yönetici işlevler", "işitme kayıplı/engelli çocuklar", "ișitme kaybı", "koklear implantlı çocuklar" ile "executive functions", "children with hearing loss", "hearing impaired children", "deaf", "hard of hearing", "cochlear implant" gibi anahtar kelimelerle çeşitli birleşimler yapılarak alanyazın taramasının birinci aşaması gerçekleştirilmiştir. Birinci aşamada ulaşılan araştırmaların referans listelerinden yola çıkarak ikinci aşama taramalar yapılmıştır.

\section{Gözden Geçirme Süreci}

Gözden geçirme sürecinde, Şekil 1'de görüldüğü üzere yapılan taramalar sonucunda 47 çalışmaya ulaşılmıştır. Çalışmaların başlık ve özetleri gözden geçirilerek 10 çalışmanın iki defa kaydedildiği görülmüş ve tek kopyaları çıkarılmıştır. Çalışmaların tam metinleri incelendiğinde, yürütücü işlevleri incelemeyen ancak yürütücü işlevlere değinen dokuz araştırma dolaylı olması nedeniyle elenmiştir. Dâhil edilme ölçütleri (a) veriye dayalı araştırma olması, (b) hakemli dergide yayınlanmış olması, (c) örneklem grubunun 18 yaş ve altı İK çocuklardan oluşması, (d) İK çocuklarda doğrudan yürütücü işlevlere odaklanması veya yürütücü işlevlerin diğer becerilerle/süreçlerle ilişkisine odaklanması şeklinde belirlenmiştir. Bu ölçütler eşliğinde sekiz çalışma örneklem grubunun 18 yaşın üstünde olması, üç çalışma bilgi verici makale olması, bir çalışma geçerlik güvenirlik çalışması olması ve bir çalışmanın da uluslararası tez olması nedenleriyle dışlanmıştır. Dâhil edilme ölçütlerine uymayan araştırmaların elenmesi sonucunda 15 görgül araştırma bu derlemenin kapsamına alınmıştır. Derlemeye alınan araştırma sayısının az olması nedeniyle kodlayıcılar arası güvenirlik hesabı yapılmamıştır. Bunun yerine araştırmanın güvenirliğini sağlamak için yazarlar 15 araştırmayı birlikte incelemişler, uzlaşma sağlayarak kodlama gerçekleştirmişlerdir. 


\section{Şekil 1}

Gözden Geçirme Süreci

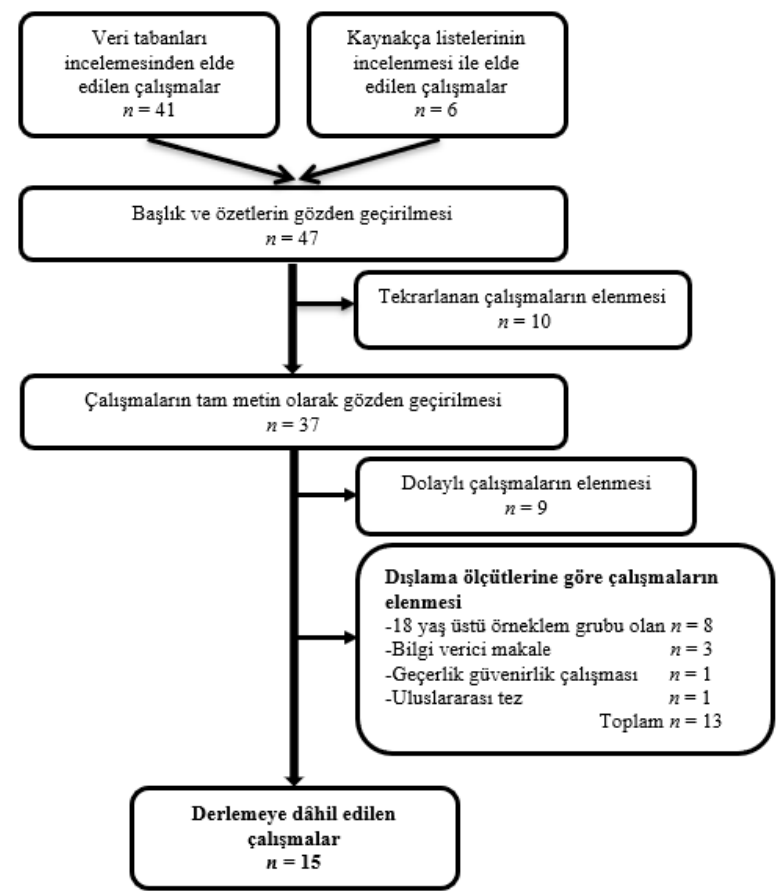

\section{Bulgular}

Bu araştırmada, İK çocuklarda bilişsel süreçlerden yürütücü işlevlere odaklanmış araştırmalardan yola çıkarak İK çocuklarda yürütücü işlevler ile diğer bilişsel süreçler/beceriler ilişkisi ve bu çocukların yürütücü işlevler performansı üzerine genel bir bakış açısı ortaya koymak amaçlanmıştır. Araştırma sorularına paralel olarak, bulgular; (a) araştırmaların yöntemsel özellikleri, (b) ana bulguları ve (c) eğitim uygulamalarına ilişkin önerileri temaları altında sunulmaktadır.

\section{Araştırmaların Yöntemsel Özellikleri}

\section{Katılımcı Özellikleri}

İK katılımcıların $(n=832)$ demografik, odyolojik ve eğitim özellikleri Tablo 1'de verilmektedir. Buna göre, katılımcıların yaşları 3 ile 18 arasında değişmektedir. Katılımcıların \%6'sında ek yetersizlik olduğu, \%68'inde ek yetersizlik olmadığı ve kalan katılımcılar için bilgi verilmediği görülmektedir. Ek yetersizliği olan çocukların büyük bir kısmında zihinsel yetersizlik bulunmaktadır. \%35'i koklear implant, \%13'ü işitme cihazı kullanmaktadır. \%6'sı ise geçmişte işitme cihazı kullanmış, \%45'inin kullandığı işitme teknolojisi belirtilmemiştir. \%61'i sözel, \%25'i işaret dili, \%11'i tüm iletişim yöntemini kullanmaktadır. \%48'i işitme engelliler okulunda, \%31'i kaynaştırma ortamlarında eğitim almakta, \%21'inin eğitimine ilişkin bilgi verilmemektedir. \%12'si erken eğitim almıştır.

\section{Araştırma Desenleri}

Tablo 1'de görüldüğü üzere konuya ilişkin yalnızca nicel araştırma yöntemleriyle desenlenen araştırmaların olduğu, nitel yöntemlerle desenlenen araştırmanın olmadığı görülmüştür. Gay ve diğerlerinin (2016) sınıflamasına göre sırasıyla nedensel-karşılaştırmalı (\%67), korelasyonel (\%27), betimsel (\%7) desen kullanılmaktadır.

\section{Ölçme Araçları}

Yürütücü işlevler için kullanılan ölçme araçları Tablo 1'de verilmektedir. Yürütücü işlevleri değerlendirmede kullanılan 19 farklı ölçme aracının \%53'ü görevlerden (tasks) oluşmaktadır. 19 ölçme aracından \%26'sının standart test, \%16'sının test bataryası, \%5'inin ölçek olduğu görülmektedir. Araştırmaların \%60'ında ölçme araçları bir uzman tarafından çocuklara doğrudan uygulanmış, \%33’ünde ebeveynlerin/öğretmenlerin cevapları, \%7’sinde uzman ve ebeveynlerin cevapları birlikte değerlendirilmiştir. 
Tablo 1

Katılımcıların Özellikleri ve Araştırmaların Belirlenmiş Kategorilere Göre Özetleri

\begin{tabular}{|c|c|c|c|c|c|c|c|c|c|c|c|}
\hline \multirow[b]{2}{*}{ ż } & \multirow[b]{2}{*}{ 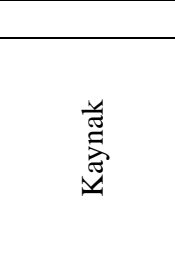 } & \multicolumn{3}{|c|}{ Demografik özellikler } & \multicolumn{2}{|c|}{ Odyoloji özellikleri } & \multicolumn{2}{|c|}{ Eğitim özellikleri } & \multirow[b]{2}{*}{ 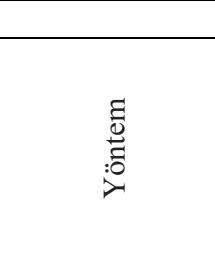 } & \multicolumn{2}{|c|}{ Araştırmaların belirlenmiş kategorilere göre özetleri } \\
\hline & & 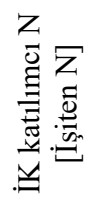 & 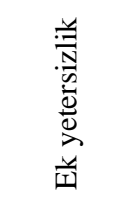 & 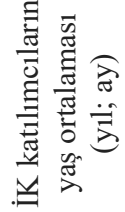 & $\stackrel{:}{:}: \frac{\vec{n}}{0}$ & 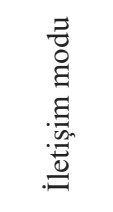 & 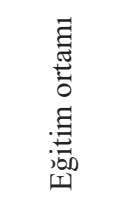 & 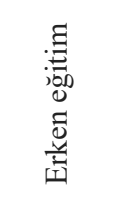 & & 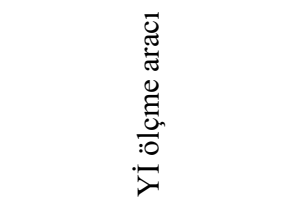 & 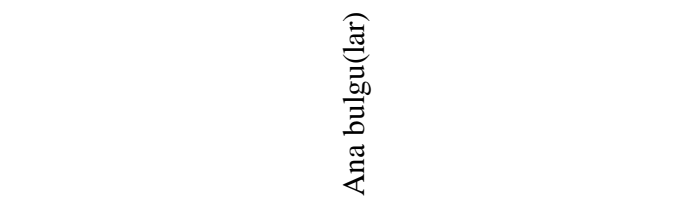 \\
\hline 1 & $\begin{array}{r}\text { Surowiecki } \\
\text { vd. (2002) }\end{array}$ & 48 & Yok & $9 ; 4$ & $\begin{array}{l}24 \mathrm{Kİ}, \\
24 \mathrm{I} C\end{array}$ & $48 \mathrm{~S}$ & $48 \mathrm{~K}$ & - & Korelasyonel & CANTAB & $\begin{array}{l}\text { Yİ'de KİÇ ve İCÇ arasında anlamlı farklılık yoktur. } \\
\text { Yİ ile konuşma algılama, sözcük dağarcığı ve dil } \\
\text { ilişkili değildir. }\end{array}$ \\
\hline 2 & $\begin{array}{l}\text { Woolfe vd. } \\
(2002)\end{array}$ & $\begin{array}{c}60 \\
{[40]}\end{array}$ & - & $6 ; 10$ & - & 60 İD & $60 \mathrm{~K}$ & - & $\begin{array}{l}\text { Nedensel- } \\
\text { karşılaştırmalı }\end{array}$ & WCST & $\begin{array}{l}\text { Anadili İD olanlar, olmayanlar ve işitenler arasında } \\
\text { Yİ'de farklılık yoktur. Yİ, ZK'daki farklılıklar için } \\
\text { açıklayıcı değildir. }\end{array}$ \\
\hline 3 & $\begin{array}{l}\text { Figueras vd. } \\
\text { (2008) }\end{array}$ & $\begin{array}{c}47 \\
{[22]}\end{array}$ & Yok & $10 ; 4$ & $\begin{array}{l}22 \mathrm{Kİ} \\
25 \mathrm{IC}\end{array}$ & $\begin{array}{l}33 \mathrm{~S} \\
13 \mathrm{TI} \\
1 \text { İD }\end{array}$ & $47 \mathrm{~K}$ & $\begin{array}{c}22 \mathrm{EE} \\
25-\end{array}$ & $\begin{array}{l}\text { Nedensel- } \\
\text { karşılaştırmalı }\end{array}$ & $\begin{array}{l}\text { NEPSY, Day-Night } \\
\text { Stroop, One-Two } \\
\text { Tasks, D-KEFS }\end{array}$ & $\begin{array}{l}\text { Yİ'de KİÇ ve İCÇ, işitenlerden düşük performansa } \\
\text { sahiptir. Yİ'de KİÇ ile İCÇ arasında farklılık yoktur. } \\
\text { İK çocuklarda Yİ ile dil ilişsilidir. }\end{array}$ \\
\hline 4 & $\begin{array}{l}\text { Remine vd. } \\
(2008)\end{array}$ & 37 & Yok & $14 ; 0$ & $\begin{array}{l}17 \mathrm{KI}, \\
20 \mathrm{I} C\end{array}$ & $37 \mathrm{~S}$ & $37 \mathrm{~K}$ & $\mathrm{EE}$ & Korelasyonel & D-KEFS & $\begin{array}{l}\text { KİÇ ve İCÇ'de Yİ ile dil becerileri arasında ilişki } \\
\text { yoktur. }\end{array}$ \\
\hline 5 & $\begin{array}{l}\text { Meristo \& } \\
\text { Hjelmquist } \\
\text { (2009) }\end{array}$ & 61 & Yok & $12 ; 2$ & - & 61 İD & $61 \mathrm{İEO}$ & - & Korelasyonel & $\begin{array}{l}\text { WISC, Corsi Block } \\
\text { Task, WCST, Go- } \\
\text { no-go Test, Conflict } \\
\text { Test }\end{array}$ & $\begin{array}{l}\text { Yİ'de başarılı olan çocukların bu başarısı ZK'ya } \\
\text { yansımamıştır. Anadili İD olmayanların YI'de } \\
\text { yaşadıkları güçlüklerin sebebi ZK'da yaşadıkları } \\
\text { güçlüklerdir. }\end{array}$ \\
\hline 6 & $\begin{array}{l}\text { Şipal \& } \\
\text { Bayhan } \\
(2010)\end{array}$ & 82 & Yok & $11 ; 11$ & - & $\begin{array}{l}16 \mathrm{İD} \\
16 \mathrm{~S} \\
50 \mathrm{TI}\end{array}$ & 82 İEO & $\begin{array}{c}39 \mathrm{EE}, \\
43-\end{array}$ & $\begin{array}{l}\text { Nedensel- } \\
\text { karşılaştırmalı }\end{array}$ & WCST & $\begin{array}{l}\text { Dil, erken eğitim ve cinsiyet Yİ üzerinde etkilidir. } \\
\text { Erken eğitim agresif davranışlar üzerinde etkili } \\
\text { değildir. Dil ve Yİ arasında karşı1lıkı bağlılık vardır. }\end{array}$ \\
\hline 7 & $\begin{array}{c}\text { Beer vd. } \\
(2011)\end{array}$ & 45 & - & $9 ; 11$ & $45 \mathrm{KI}$ & $\begin{array}{l}37 \mathrm{~S}, \\
8 \mathrm{TI}\end{array}$ & - & - & Betimsel & BRIEF & $\begin{array}{l}\text { KİÇ Yİ'nin bazı alanlarında (engelleme kontrolü, } \\
\text { çalışma belleği ve davranısssal düzenleme) güçlük } \\
\text { yaşarlar. Bu güçclükler konuşma ve dil ile ilişkilidir. }\end{array}$ \\
\hline 8 & $\begin{array}{l}\text { Oberg \& } \\
\text { Lukomski } \\
(2011)\end{array}$ & 22 & $\begin{array}{l}8 \text { ÖG, } \\
8 \mathrm{GY} \\
4 \mathrm{DE} / \mathrm{H} \\
1 \mathrm{ZY} \\
1 \mathrm{~B}\end{array}$ & $11 ; 9$ & $\begin{array}{l}2 \mathrm{KI}, \\
8 \dot{\mathrm{IC}}, \\
12 \dot{\mathrm{IC}} \\
(\mathrm{GK})\end{array}$ & 22 İD & 22 İEO & - & Korelasyonel & BRIEF, WCST-C4 & $\begin{array}{l}\text { KİÇ ve İCÇ’nin Yİ performanslarında ebeveynlerin } \\
\text { ve öğretmenlerin raporlarında benzer sonuçlar } \\
\text { çıkmıstır. Ebeveyn ve öğretmen raporları ile } \\
\text { doğrudan uygulanan ÖDA arasında da benzer } \\
\text { sonuçlar çıkmıştır. İşitme kaybı genetik olanlar } \\
\text { Yİ'de daha başarılıdır. }\end{array}$ \\
\hline
\end{tabular}


Tablo 1 (devami)

\begin{tabular}{|c|c|c|c|c|c|c|c|c|c|c|c|}
\hline \multirow[b]{2}{*}{$\stackrel{\circ}{z}$} & \multirow[b]{2}{*}{ 䔍 } & \multicolumn{3}{|c|}{ Demografik özellikler } & \multicolumn{2}{|c|}{ Odyoloji özellikleri } & \multicolumn{2}{|c|}{ Eğitim özellikleri } & \multirow[b]{2}{*}{ 麦 } & \multicolumn{2}{|c|}{ Araştırmaların belirlenmiş kategorilere göre özetleri } \\
\hline & & 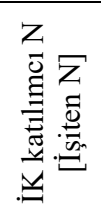 & 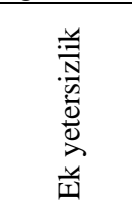 & 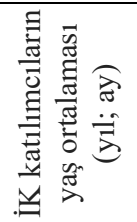 & 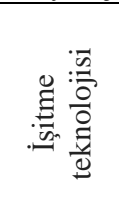 & 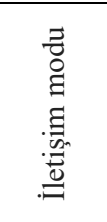 & 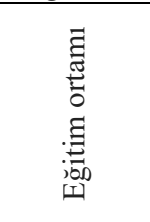 & 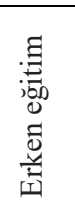 & & 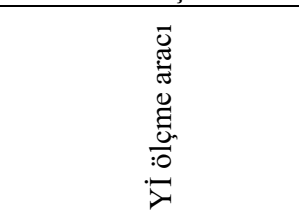 & 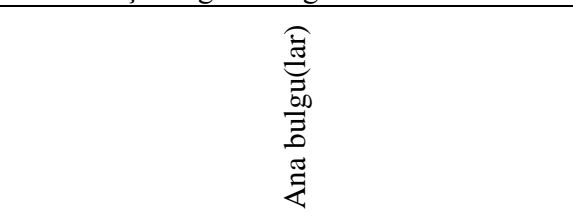 \\
\hline 9 & $\begin{array}{l}\text { De Villiers \& } \\
\text { De Villiers } \\
(2012)\end{array}$ & $\begin{array}{c}45 \\
{[45]}\end{array}$ & - & $5 ; 1$ & $\begin{array}{l}25 \mathrm{KI}, \\
20 \mathrm{IIC}\end{array}$ & $45 \mathrm{~S}$ & 45 İEO & - & $\begin{array}{l}\text { Nedensel- } \\
\text { karşılaştırmalı }\end{array}$ & $\begin{array}{l}\text { Day-Night Stroop, } \\
\text { NEPSY, DCCS }\end{array}$ & $\begin{array}{l}\text { Yİ, KİÇ ve İCÇ'de ZK (aldanma) için } \\
\text { yordayıcıdır. }\end{array}$ \\
\hline 10 & $\begin{array}{l}\text { Hintermair } \\
(2013)\end{array}$ & 214 & $\begin{array}{l}184 \text { yok, } \\
13 \mathrm{~B}, \\
11 \mathrm{ZY} \\
6 \mathrm{DE} / \mathrm{H}\end{array}$ & $12 ; 5$ & $\begin{array}{l}52 \mathrm{KI}, \\
162-\end{array}$ & $\begin{array}{l}191 \mathrm{~S} \\
23 \mathrm{TI}\end{array}$ & $\begin{array}{l}145 \text { İEO, } \\
69 \mathrm{~K}\end{array}$ & - & $\begin{array}{l}\text { Nedensel- } \\
\text { karşılaştırmalı }\end{array}$ & BRIEF & $\begin{array}{l}\text { Yİ'de KİÇ işitenlere göre güçlük yaşarlar. } \\
\text { K'daki KIÇ, İEÖ'deki KIÇ’e göre Yİ'de } \\
\text { daha başarılidır. İletişim ve davranış } \\
\text { problemleri Yİ ile ilişkilidir. }\end{array}$ \\
\hline 11 & $\begin{array}{l}\text { Nazarzadeh vd. } \\
\text { (2014) }\end{array}$ & $\begin{array}{c}20 \\
{[10]}\end{array}$ & - & $10 ; 0$ & $\begin{array}{l}10 \mathrm{KI}, \\
10-\end{array}$ & - & - & - & $\begin{array}{l}\text { Nedensel- } \\
\text { karş1laştırmalı }\end{array}$ & $\begin{array}{l}\text { Coolidge } \\
\text { Neuropsychological } \\
\text { and Personality Test }\end{array}$ & $\begin{array}{l}\text { KİÇ ve diğer İK çocukların, işiten çocuklara } \\
\text { göre YI'de (organize etme, planlama, karar } \\
\text { verme, engelleme) performansları } \\
\text { düşüktür. KİÇ ile İK çocuklarda Yİ ile ZK } \\
\text { arasında ilişki yoktur. }\end{array}$ \\
\hline 12 & Beer vd. (2014) & $\begin{array}{c}24 \\
{[21]}\end{array}$ & Yok & $4 ; 6$ & $24 \mathrm{KI}$ & $24 \mathrm{~S}$ & - & - & $\begin{array}{l}\text { Nedensel- } \\
\text { karşılaştırmalı }\end{array}$ & $\begin{array}{l}\text { BRIEF, BRIEF-P, } \\
\text { NEPSY-II, Leiter-R, } \\
\text { Beery VMI }\end{array}$ & $\begin{array}{l}\text { KİÇ’ın, işitenlere göre Yİ'nin alanlarında } \\
\text { (ketleme, konsantrasyon, çalışma belleği) } \\
\text { performansı daha düşüktür. KİÇ ve } \\
\text { işitenler arasında görsel hafiza ve organize } \\
\text { etme-tamamlamada farlılık yoktur. } \\
\text { Ebeveynlere göre KICÇ'de Yİ ile dil } \\
\text { ilişkilidir fakat doğrudan uygulanan } \\
\text { ÖDA'ya göre Yİ ile dil arasında ilişki } \\
\text { yoktur. KİÇ'de Yİ'deki düşük performans } \\
\text { okulöncesi dönemde belirlenebilmektedir. }\end{array}$ \\
\hline 13 & $\begin{array}{l}\text { Daza vd. } \\
(2014)\end{array}$ & 30 & Yok & $10 ; 8$ & $\begin{array}{l}15 \mathrm{KI}, \\
15 \dot{\mathrm{IC}}\end{array}$ & $\begin{array}{l}23 \mathrm{~S} \\
7 \mathrm{ID}\end{array}$ & - & - & $\begin{array}{l}\text { Nedensel- } \\
\text { karş1laştırmal1 }\end{array}$ & WISC-IV & KİÇ ve İCÇ'de Yİ ile okuma ilişkilidir. \\
\hline
\end{tabular}


Tablo 1 (devami)

\begin{tabular}{|c|c|c|c|c|c|c|c|c|c|c|c|}
\hline \multirow[b]{2}{*}{ z } & \multirow[b]{2}{*}{ 䒿 } & \multicolumn{3}{|c|}{ Demografik özellikler } & \multicolumn{2}{|c|}{ Odyoloji özellikleri } & \multicolumn{2}{|c|}{ Eğitim özellikleri } & \multirow[b]{2}{*}{ : } & \multicolumn{2}{|c|}{ Araştırmaların belirlenmiş kategorilere göre özetleri } \\
\hline & & 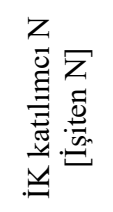 & 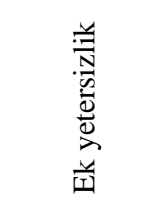 & 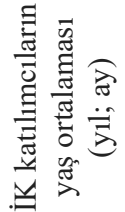 & 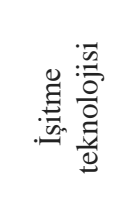 & 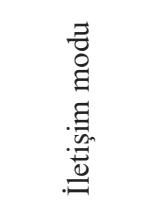 & 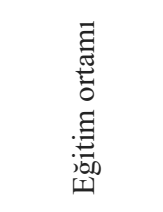 & 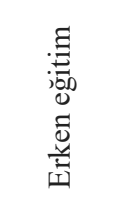 & & 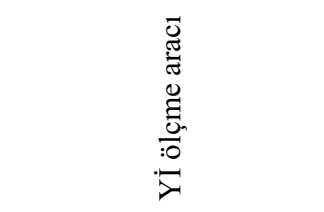 & 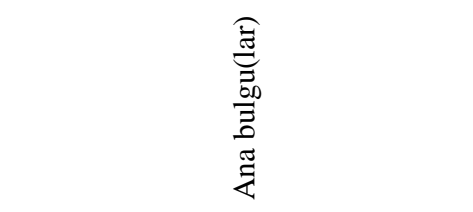 \\
\hline 14 & $\begin{array}{l}\text { AuBuchon vd. } \\
\text { (2015) }\end{array}$ & $55[55]$ & Yok & $15 ; 4$ & $55 \mathrm{KI}$ & $55 \mathrm{~S}$ & - & - & $\begin{array}{l}\text { Nedensel- } \\
\text { karş1laştırmalı }\end{array}$ & $\begin{array}{l}\text { WISC-3, Stroop Color, } \\
\text { Word Test, Trail } \\
\text { Making Test, Variables } \\
\text { of Attention Test }\end{array}$ & $\begin{array}{l}\text { KİÇ’ın Yİ peformansı işitenlere göre } \\
\text { düşüktür. KİÇ'de STH ile Yİ'nin } \\
\text { bazı alanları (çalışma belleği, } \\
\text { konuşma akıc1lığı, ketleme, } \\
\text { konsantrasyon) ilişsili değildir. } \\
\text { KİÇ'de AKH ile YI'nin bazı } \\
\text { alanları (çalışma belleği, konuşma } \\
\text { akıcıllğı, ketleme, konsantrasyon) } \\
\text { ile ilişkilidir. }\end{array}$ \\
\hline 15 & Hall vd. (2017) & $42[45]$ & - & $8 ; 0$ & $\begin{array}{l}2 \mathrm{Kİ}, 40 \\
\text { İC (GK) }\end{array}$ & 42 İD & 42 İEO & - & $\begin{array}{l}\text { Nedensel- } \\
\text { karşılaştırmalı }\end{array}$ & BRIEF & $\begin{array}{l}\text { Anadili İD olan İK çocuklar Yİ'de } \\
\text { ve davranış problemlerinde işiten } \\
\text { akranlarıyla benzer özellikler } \\
\text { gösterirler. Anadili İD olan İK } \\
\text { çocuklar sadece ketleme ve çalı̧ma } \\
\text { belleği görevlerinde risk belirtisi } \\
\text { göstermişlerdir. }\end{array}$ \\
\hline & Toplam & $\begin{array}{c}832 \\
{[238]}\end{array}$ & $\begin{array}{l}568 \text { Yok }> \\
212->14 \\
\text { B > } 12 \mathrm{ZY}, \\
10 \mathrm{DE} / \mathrm{H}, 8 \\
\text { ÖG, } 8 \mathrm{GY}\end{array}$ & $10 ; 2$ & $\begin{array}{c}375-> \\
293 \mathrm{KI}> \\
112 \dot{\mathrm{I} C}> \\
52 \dot{\mathrm{I} C} \\
(\mathrm{GK})\end{array}$ & $\begin{array}{c}509 \mathrm{~S}> \\
209 \mathrm{IID}> \\
94 \mathrm{TI}>20 \\
-\end{array}$ & $\begin{array}{c}397 \text { IEOO > } \\
261 \mathrm{~K}> \\
174-\end{array}$ & $\begin{array}{l}734-> \\
98 \mathrm{EE}\end{array}$ & & & \\
\hline
\end{tabular}

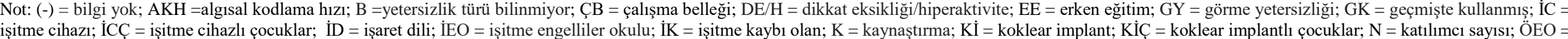
özel eğitim okulu; ÖG = öğrenme güçlüğ̈̈; S = sözlü iletişim; STH = sözel tekrar hızı; Tİ = tüm iletişim; Yİ = yürütücü işlevler; ZK = zihin kuramı; ZY = zihinsel yetersizlik. 


\section{Araştırmaların Ana Bulguları}

Ana bulgular (a) yürütücü işlevlerin diğer bilişsel süreçlerle/becerilerle ilişkisi, (b) İK çocukların yürütücü işlevler performansı ve karşılaştırmalı sonuçlar (işiten, İK, koklear implantlı, işitme cihazlı, anadili işaret dili olan/olmayan çocuklar), (c) yürütücü işlevlerin etkilediği ve etkilendiği süreçler/beceriler/faktörler olmak üzere üç tema altında incelenmiştir.

\section{Yürütücü İslevlerin Diğer Bilişsel Süreçlerle/Becerilerle İlişkisi}

Araştırmaların \%60’1 yürütücü işlevlerin diğer bilişsel süreçlerle/becerilerle ilişkili veya ilişkisiz olduğuna ilişkin bilgi vermektedir. Buna göre Şekil 2'den izlenebileceği üzere yürütücü işlevler, araştırmaların \%27'sinde dil (dil ve iletişim), \%7'sinde okuma, \%7'sinde bellek (algısal kodlama hızı), \%7'sinde davranış problemleri ile ilişkili bulunmuştur. Diğer taraftan, Şekil 3'te görüldüğü gibi ilginç biçimde aynı oranda yürütücü işlevler araştırmaların \%27'sinde dil (dil, konuşma algılama), \%7'sinde bellek (sözel tekrar hızı), \% 7'sinde okuma (sözcük dăgarcı̆̆l) ve \%7'sinde zihin kuramı ile ilişkisiz bulunmuştur.

\section{Şekil 2}

Yürütücü İşlevler ile Diğer Bilişsel Süreçler/Beceriler Arasında İlişki Saptayan Araştırmalar

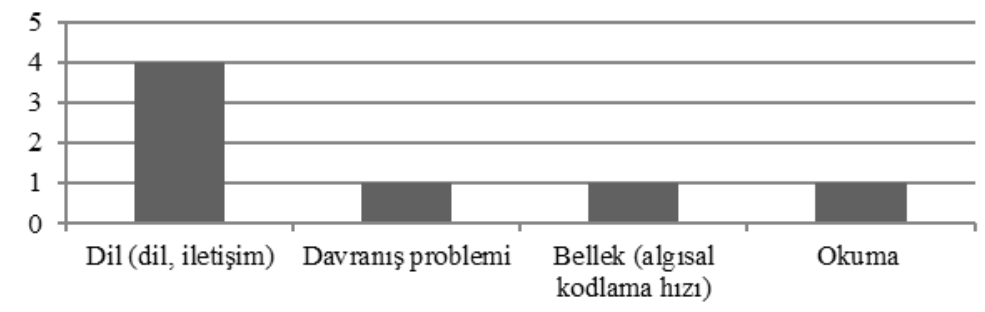

\section{Şekil 3}

Yürütücü Işlevler ile Diğer Bilişsel Süreçleri/Becerileri İlişkisiz Saptayan Araştırmalar

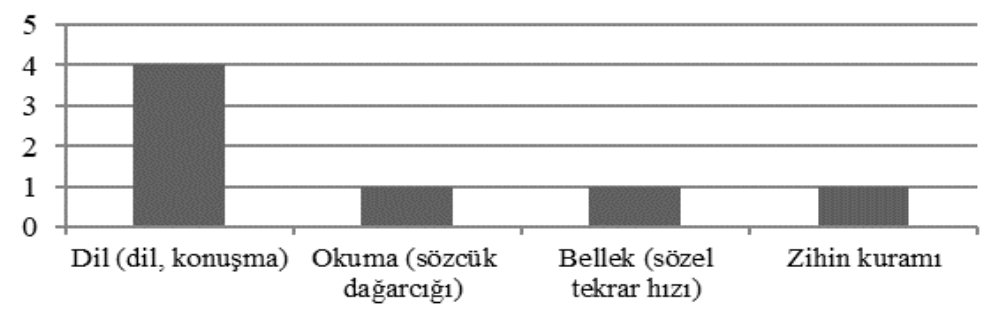

\section{İK Çocukların Yürütücü İşlevler Performansı ve Karşılaştırmalı Sonuçlar}

Araştırmaların \%67'sinde İK çocukların yürütücü işlevler performansı ve karşılaştırmalı sonuçları verilmektedir. Karşılaştırmalar işiten, İK, koklear implantlı, işitme cihazlı, anadili işaret dili olan çocuklar arasında yapılmıştır. \%40’’na göre koklear implantlı ve işitme cihazlı çocukların, işiten akranlarına göre yürütücü işlevlerde güçlük yaşadıkları ortaya çıkmaktadır. \%13'ü koklear implantlı ve işitme cihazlı çocuklar arasında yürütücü işlevler performansında farklılık olmadığını göstermektedir. Bununla birlikte \%13'ünde de anadili işaret dili olan çocuklar ile işiten çocuklar arasında farklılık olmadığı belirtilmektedir. Kaynaştırma ortamındaki koklear implantlı çocukların işitme engelliler okulundaki koklear implantlı çocuklara göre (\%7) ve işitme kaybı genetik olanların yürütücü işlevlerde daha başarılı oldukları (\%7) görülmektedir.

\section{Yürütücü İşlevlerin Etkilediği ve Etkilendiği Süreçler/Beceriler/Faktörler}

Araştırmaların \%33'ü yürütücü işlevlerin etkilediği ve etkilendiği süreçleri/becerileri/faktörleri göstermektedir. Sırasıyla zihin kuramı (\%13), erken eğitim (\%7), dil (\%7) ve cinsiyet (\%7) yürütücü işlevleri etkilemektedir. Bir araştırma da (\%7) yürütücü işlevlerin zihin kuramı için açıklayıcı olmadığını göstermektedir. Ayrıca yürütücü işlevlerde yaşanan güçlüklerin okul öncesi dönemde belirlenebileceği de belirtilmektedir (\%7). 


\section{Araştırmaların Eğitim Uygulamasına Yönelik Sunduğu Öneriler}

Araştırmaların \%40’ında eğitim uygulamasına yönelik öneriler görülmektedir. Yürütücü işlevlerin desteklenebilmesi için erken tanıdan sonra tercih edilen iletişim yöntemine uygun biçimde aile katılımlı erken eğitim programlarına devam edilmesi önerilmektedir. Ayrıca işitme kaybının etiyolojisi hakkında detaylı bilginin edinilmesi vurgulanmaktadır. Vygotsky'nin sosyo-kültürel gelişim kuramı, bilişsel beceriler için destekleyici bulunmakta, bu nedenle erken eğitim programlarında benimsenmesine dikkat çekilmektedir. Vygotsky’e göre, çocuklar yetişkinlerle geçirdikleri etkileşimlerinde yeni zihinsel süreçler geliştirirler. Yetişkinlerle geçirdikleri yaşantılardan sonra çocuklar bu zihinsel süreçleri kendi kendine içselleştirerek bağımsız biçimde kullanmaya başlarlar. Dolayısıyla Vygotsky'nin kuramında yetişkinlerin sağladıkları etkileşimler ve eğitim ortamlarında yaptıkları çevresel düzenlemeler çocukların yeni zihinsel süreçleri geliştirmelerinde önemli bulunmaktadır (Bodrova \& Leong, 1996/2013). Bu nedenle eğitim programlarında yeterince erken dönemde yürütücü işlevleri destekleyici oyunlara ve etkinliklere yer verilerek İK çocuklara düşünme ve problem çözme stratejilerinin öğretilmesi önerilmektedir. Hem bireysel hem de grup etkinliklerinde dil temelli aktivitelerin yanında dengeli ilerleyen problem çözme, duygusal ve davranışsal düzenleme, öz denetim ve öz düzenleme becerilerine yönelik etkinliklerin de dikkate alınması önemli bulunmaktadır.

\section{Tartışma}

Sistematik derleme yoluyla İK çocuklarda yürütücü işlevlerin diğer bilişsel süreçlerle/becerilerle ilişkisi ve bu çocukların yürütücü işlevler performansı üzerine genel bir bakış açısı ortaya koymanın amaçlandığı bu araştırmada elde edilen bulgular alanyazınla birlikte tartışılmaktadır.

\section{Araştırmaların Yöntemsel Özellikleri}

Araştırmanın yöntemsel özellikleri kapsamında öncelikle katılımcıların demografik, odyolojik ve eğitimsel özellikleri ele alınmıştır. Buna göre araştırmalardaki 3-18 yaş İK çocukların toplam sayısı 832'dir. İK çocuklar sık rastlanılan bir grup olmamasına rağmen, araştırmalarda yeterli sayıda İK çocuk katılımcısı bulunduğu gözlenmektedir. Oysaki yaş, cinsiyet, işitme kaybı derecesi ve türü, iletişim yöntemi, kullanılan işitme teknolojisi, eğitim ortamı gibi özellikler bakımından homojen bir grup oluş̧urulması oldukça zor olan bir gruptur (Leigh, 2008). Araştırmaların \%47'sinde işiten çocuklar norm grubu olarak kabul edilmiştir. Özel eğitim araştırmalarında norm grubu olarak kabul edilen grup tipik gelişim gösteren çocuklardır. Bu nedenle bu araştırmalarda da normal sınırlarda işiten çocukların norm grubu olarak kabul edilmesi makul bir durumdur (Braden, 2001). Bu bakış açısı kaynaştırma/bütünleştirme felsefesi ile ilişkilendirilebilir. Bütünleştirmenin felsefesi tüm çocukların aynı eğitim ortamında eğitim almaları ise (Hornby, 2014), İK çocuklar için norm olarak kabul edebileceğimiz grubun işiten çocuklar olması gerektiği söylenebilir.

Araştırmaların büyük bir kısmında, IKK çocuklar için önemli olan tanı yaşı, koklear implant kulanmaya başlama yaşı ve kullanma süresine ilişkin bilgilere rastlanmamaktadır. Tablo 1'den elde edilen bulgular katılımcıların \%35'inin koklear implant kullandığını, \%61'inin sözel iletişim yöntemini benimsediğini, \%48'inin işitme engelliler okulunda eğitime devam ettiğini, sadece \%12'si için erken eğitim bilgisinin olduğunu göstermektedir. Bununla birlikte İK çocukların odyoloji ve eğitim özelliklerine ilişkin detaylı bilgilerin verildiği araştırmalarla birlikte bilgi verilmeyen araştırmalar da bulunmaktadır. Oysaki odyoloji ve eğitim özellikleri başlıkları altında incelenen özellikler İK çocukların bilişsel ve diğer gelişim alanlarını doğrudan etkileyebilecek özelliklerdir. Araştırmalarda bu bilgilerin eksik olmasının nedeni geçmiş bilgilerin kayıtlı olmamasından kaynaklanabilir. Ortaya çıkan odyoloji ve eğitim özellikleri İK çocukların heterojen bir grup oldukların tekrar göstermekte ve İK çocukların erken müdahalesi için Bebeklik Dönemi İşitmenin Değerlendirilmesi Komitesi (Joint Committee on Infant Hearing [JCIH], 2013) tarafindan belirlenen evrensel standartlara henüz ulaşılamadığına işaret etmektedir. JCIH (2013), IK çocukların en geç üç ay içinde tanılanması, en geç altı ay içinde cihazlandırılmasıyla birlikte erken çocukluk eğitimi programına başlamalarını önermektedir. Buradaki amaç, İK çocukların erken eğitimden sonra en az kıstllayıcı eğitim ortamlarında eğitim hayatlarına devam etmelerini sağlamaktır.

Özel gereksinimli çocuklar için eğitim ortamları en çok kısıtlayıcıdan en az kısıtlayıcı ortama göre sıralandı̆̆ında işitme engelliler okulu en çok kısıtlayıcı ortam iken kaynaştırma en az kısıtlayıcı ortam olarak nitelendirilmektedir (Kargın, 2004). Günümüzde yasal düzenlemelerle ve araştırmalarla kaynaştırma/bütünleştirme ilkesi desteklenmektedir. Ancak büyük bir kısmının koklear imlant kullanıyor olması ve en çok tercih edilen iletişim yönteminin sözel olması düşünüldüğünde, çocukların neredeyse yarısının en çok kısıtlayıcı ortamlarda eğitim aldıklarının görülmesi şaşırtıcı bir bulgudur. JCIH'ın (2013) belirlediği evrensel standartları ve alanyazının önerileri temel alındığında, derlemedeki İK çocuklara $(n=832)$ odyolojik yönetim ve 
eğitim olanakları açısından yeterli koşulların sağlanamadığı söylenebilir. Oysaki alanyazında yürütücü işlevlerin erken yaşlarda başlayıp yetişkinlik dönemine kadar gelişim gösterdiği belirtilmektedir (Beer vd. 2014; Beer vd., 2010; Hughes vd., 2004). Bu durumda İK çocukların tüm gelişim alanlarını desteklediği bilinen erken eğitimin yürütücü işlevler becerilerini de destekleyeceği rahatllkla söylenebilir. Odyolojik ve erken eğitim anlamında gerekli koşullar sağlanmamışsa İK çocuklar için genelde bilişsel becerilerde, özelde yürütücü işlevlerde, büyük bir beklentiye girmenin yanlış olacağı söylenebilir. Sonuç olarak İK çocukların işitsel deneyimleri, kullandıkları işitme teknolojileri, benimsedikleri iletişim yöntemleri, eğitim geçmişleri ve eğitim ortamlarındaki çeşitlilik genel ve bireyselleştirilmiş eğitim programları, öğretmenler, öğretmen yetiştiren kurumlar ve eğitim araştırmalarındaki güçlükleri de beraberinde getirmektedir (Leigh, 2008).

Nitel yöntemle yürütülmüş hiçbir araştırmaya rastlanmayan bu derlemede en çok tercih edilen nicel araştırma modeli nedensel-karşılaştırmalı olup, onu korelasyonel model takip etmektedir. Bu durumun nedenini anlamak için araştırma modellerinin doğasına bakmanın gerekli olduğu düşünülmektedir. Nedensel karşılaştırma modeli, doğal ortamda kendiliğinden oluşan bir değişkene dikkat çeker ve olay öncesi durum üzerinde kontrol mümkün değildir (Gay vd., 2016). İşitme kaybı da araştırmacı tarafından oluşturulan bir durum değildir ve işitme kaybı öncesini kontrol altına almak günümüz için mümkün değildir. Bu nedenle İK çocuklar için yapılan bu araştırmalarda en çok nedensel-karşılaş̧ırmalı modelin tercih edilmesi anlaşılır bulunmaktadır. Korelasyonel araştırma modeli ise, iki ya da daha fazla değişkenin değişim ilişkisini inceleyen fakat neden-sonuç ilişkisi vermeyen modeldir (Gay vd., 2016). Giriş kısmında da belirtildiği üzere yürütücü işlevler ile dil arasında bir ilişki olduğu varsayılmaktadır. Dolayısıyla bu modelin kullanılmasının nedenini, yürütücü işlevler ile diğer bilişsel süreçler/beceriler arasındaki ilişkinin bilinmesine duyulan ihtiyaç karşılamaktadır. Doğan ve Hasanoğlu'unun (2016) yaptıkları içerik analizindeki sonuçlarda da araştırmaların en çok nedensel-karşılaştırmalı ve korelasyonel araştırma ile desenlenmiş olması İK çocuklarda bilişsel süreçlere ilişkin yapılan araştırmalara yönelik yöntemsel eğilim hakkında fikir sağlamaktadır. İlerleyen yıllarda İK çocuklarda bilişsel becerileri geliştirmeyi amaçlayan müdahale programları tasarlanması halinde deneysel araştırmaların artacağı ileri sürülebilir.

Yürütücü işlevler, kendi içinde çok fazla bileşen/beceri içermesiyle ölçülmesi oldukça karmaşık bir beceri olarak kabul edilmektedir. Yürütücü işlevlerin ölçümünde, ölçüm riskini önlemek için birden çok ölçme aracı ve standartlaştırılmış ölçme araçlarının kullanılması önerilmektedir (Barkley, 2012; Hall vd., 2017). Toplamda 19 farklı ölçme aracının kullanılması, araştırmaların çoğunda birden çok ölçme aracı ile yürütücü işlevlerin ölçülmesi araştırmalarda genel olarak ölçüm güvenirliğine dikkat edildiğine işaret etmektedir. Araştırmalarda ölçümlerin yapılmasında en çok uzmanların doğrudan ölçümlerine başvurulmuştur. Bu da araştırmalarda en çok doğrudan ölçüme başvurulduğunu göstermektedir.

\section{Araştırmaların Ana Bulguları}

Araştırmanın ikinci sorusu ile ortaya konmak istenen araştırmaların ana bulguları; a) yürütücü işlevlerin diğer bilişsel süreçlerle/becerilerle ilişkisi, (b) İK çocukların yürütücü işlevler performansı ve karşılaştırmalı sonuçlar (işiten, İK, koklear implantlı, işitme cihazlı, anadili işaret dili olan çocuklar), (c) yürütücü işlevlerin etkilediği ve etkilendiği süreçler//beceriler/faktörler olmak üzere üç tema altında toplanmıştır.

$\mathrm{Bu}$ araştırmanın gerçekleşmesindeki itici güç, alanyazında rastlanan yürütücü işlevler ile dil arasında ilişki olduğu varsayımı olmuştur (Beer vd., 2014; Hall vd., 2017). Bu nedenle, bulguların yürütücü işlevler ile dilin aynı oranda ilişkili ve ilişkisiz olduğunu göstermesi şaşırtıcı olmuştur. Yürütücü işlevler ile ilişkili olan süreçler aynı oranda davranış problemi, bellek ve okuma şeklinde çıkarken, yürütücü işlevler ile ilişkisiz olan süreçler yine aynı oranda okuma, bellek ve zihin kuramı olarak ortaya çıkmıştır. Dolayısıyla elde edilen ana bulgular yürütücü işlevler ile bir başka bilişsel süreçler/beceriler ilişkisi hakkında bilgi sağlamamaktadır. Çok sayıda araştırmanın olmaması, alanyazın için yeni bir konu olması bu durumun nedenleri olarak gösterilebilir. Bununla birlikte yürütücü işlevler öz düzenleme, sözcüklerin aracılık etmesi, çalışma belleği, ardışık işleme gibi süreçlerin gerçekleşmesinde kullanılan araçlar ve deneyimler sağlaması ile konuşma becerilerinin gelişiminde etkili bulunmaktadır (Beer, vd., 2011; Kronenberger vd., 2013). Diğer taraftan Hall ve diğerleri (2017), anadili işaret dili olan ve işiten çocuklarla yaptıkları araştırma ile yürütücü işlevler performansında erken yaşlarda dil yoksunluğunun önemli bir belirleyici olduğunu vurgulamışlardır. Çünkü bu araştırmanın bulguları, anadili işaret dili olanların (ebeveynlerinde ve kendisinde işitme kaybı olup, doğumdan itibaren işaret dilini benimseyen çocuk) işitenlerle aralarında farklılık olmadığını ancak yine de bu İK çocukların ketleme ve çalışma belleği görevlerinde risk altında olduklarını göstermiştir. Bu noktadan hareketle işitsel yoksunlukla birlikte erken yaşlardaki dil yoksunluğunun da yürütücü işlevlerde güçlük yaşanabileceğine işaret edebileceği söylenebilir. Sonuç olarak, şimdilik yürütücü işlevler ile dil arasındaki ilişkinin nedensellikten çok karşılıklılık içinde olduğu söylenebilir. Ancak bu ilişkinin netleştirilebilmesi için daha çok sayıda araştırmaya ihtiyaç olduğu düşünülmektedir. 
İK çocukların (koklear implant ve işitme cihazı kullanan) işiten akranlarından geri kalması diğer bilişsel süreçleri inceleyen bazı araştırma bulgularıyla tutarlıdır (Ör., Bharadwaj \& Mehta, 2016; Huber vd., 2014; Lyxell vd., 2009). Koklear implant ve işitme cihazı kullanan çocuklar karşılaştırıldığında benzer performans göstermeleri, çocukların tanı yaşı, koklear implant yaşı ve süresi, erken eğitim, aile katılımı ve güncel eğitim ortamı gibi değişkenlerle açıklanabilir. Fakat Tablo 1'de de görüldüğü üzere araştırmalar geçmiş bilgileri gerektiren bu değişkenlere ilişkin tam bilgi sağlamamaktadır. Koklear implant normal işitmeyi sağlamamaktadır. Ancak özellikle iki yaşa kadar koklear implant kullanmaya başlayan ve nitelikli erken eğitimle desteklenen çocukların dil, bilişsel ve sosyal-duygusal gelişim alanlarında önemli derecede gelişme gösterdikleri bilinmektedir (Ingvalson vd., 2014; Laugen vd., 2016; May-Mederake, 2012; Netten vd., 2015; Sugaya vd., 2015). Koklear implantl1 çocuklarda yürütücü işlevleri etkileyen faktörlerin ve yürütücü işlevlerle ilişkili olan süreçlerin/becerilerin bilinmesi "Bazı koklear implantl çocuklar işiten akranlarına yetişsirken bazıları neden işiten akranlarına göre çok geri kalmaktadırlar? " sorusunun cevabı için önemli bir gelişme yaratacağı düşünülmektedir. Bu nedenlerle yürütücü işlevleri etkileyen faktörlerin ve yürütücü işlevler ile ilişkili olan becerilerin/süreçlerin bilinmesinin erken tanı, cihazlandırma ve eğitim için yeni önerilerin geliştirilmesine yardımcı olacağına inanılmaktadır (Niparko vd., 2010).

Kaynaştırma ortamındaki koklear implantlı çocukların işitme engelliler okulundakilere göre yürütücü işlevlerde daha başarılı olmaları ise en az kısıtlayıcı eğitim ortamının İK çocukların dil, bilişsel, sosyal-duygusal gelişimleri ve akademik becerileri üzerindeki olumlu etkisi ile açılanabilmektedir (Marschark \& Knoors, 2012). Erken eğitimin yürütücü işlevler üzerinde etkili faktör olarak çıkması alanyazınla tutarlıdır. Erken eğitim, özel gereksinimli çocukların okul ve yetişkinlik yılları için gelişimsel temelleri oluşturmayı ve tipik gelişim gösteren akranlarıyla arasındaki farkı azaltmayı hedeflemektedir (Bruder, 2010; Howard vd., 2010, 2011).

\section{Araştırmaların Eğitim Uygulamasına Yönelik Sunduğu Öneriler}

Ortaya çıkan öneriler, İK çocuklarda yürütücü işlevlerin desteklenebilmesi için erken tanı, erken cihazlandırma ve erken eğitime vurgu yapmaktadır. Erken tanının, cihazlandırmanın ve eğitimin İK çocukların tüm gelişim alanlarını önemli derecede desteklediği bilinmektedir. Özellikle Vygotsky'nin kuramının temel alındığı erken eğitim programlarının önerildiği görülmektedir. Bunun nedenini kuramın temelinde yer alan (a) çocuğun bugün yetişkin yardımıyla yapabildiğini yarın tek başına yapabilmesi, (b) çocuğun gelişiminde nicelikten çok niteliğin önemli bulunması düşünceleri oluşturmaktadır. Vygotsky, kuramında çocuğun öğrenmesini ve gelişimini temelde iki kavramla açıklamaktadır. Birincisi, yakınsal gelişim alanıdır. Buna göre, çocuğun iki farklı geliş̧im düzeyi vardır: (a) Çocuğun doğuştan getirdiği beceriler olup yetişkin yardımı olmadan yapabildikleridir. (b) Çocuğun yetişkin yardımı ile yapabildikleridir. Bu iki beceri düzeyi arasında kalan boşluk yakınsal gelişim alanıdır. İkincisi, çocuğun öğrenme hedefine başarılı bir şekilde ulaşması için yetişkin tarafından oluşturulan etkileşim ortamı/sağlanan destek olarak açıklanan iskele kurmadır (Vygotsky, 1954, 1998). Bu özellikler temel alınarak oluşturulan erken eğitim programlarında çocuğun tüm gelişim alanlarının desteklenmesi mümkün olduğu için yürütücü işlevlerin de destekleneceği düşünülmektedir. Erken çocukluk dönemi insan yaşamının temelini oluşturan bir dönemdir. İnsan yaşamında değişimin ve gelişimin en hızlı olduğu dönem olup, bilişsel gelişim için kritik yıllardır. Doğumdan altı yaşa kadar geçen dönem de yaşamın diğer yıllarına kıyasla bilişsel gelişim açısından son derece değerli yıllardır (Berk, 2008; Santrock, 2013). Bu nedenle erken çocukluk döneminde sağlanan zengin öğrenme ortamı, çocuklar için yaşama iyi bir başlangıç oluşturarak sonraki okul ve yetişkinlik yıllarına önemli katkılar sağlamaktadır.

Alanyazında İK çocukların erken çocukluk eğitiminin 0-3 yaş döneminde aileyi merkeze alan bireyselleştirilmiş aile eğitimi programlarının benimsendiği görülmektedir (Decker \& Vallaton, 2016; ErtürkMustul vd., 2016; Glaneman vd., 2013; Moeller vd., 2013; Turan, 2019; Turan vd., 2019). Bu aile eğitimi programlarında çocuğu bulunduğu gelişim düzeyinden bir üst düzeye çıkarmayı hedefleyen her bir gelişim alanına (işitme, konuşma üretimi, iletişim, dil [alıcı ve ifade edici] ve bilişsel) yönelik amaçlar belirlenmektedir. Bu amaçların gerçekleştirilmesi için etkin ögrenme ortamları olan oyunlar, günlük rutinler ve etkinliklere (müzik, erken okuryazarlık, sanat vb.) yer verilmektedir (Brown \& Nott, 2005; Ertürk-Mustul vd., 2016). 3-6 yaş erken çocukluk eğitimi programlarında ise serbest oyun, erken okuryazarlık etkinlikleri, matematiğe hazırlık, fen ve doğa, müzik ve sanat etkinlikleri çerçevesinde uygun amaçlarla çocukların tüm gelişim alanlarının desteklendiği bilinmektedir. Dolayısıyla erken çocukluk eğitimi programlarında oyunlar, rutinler ve etkinliklerin içine yerleştirilen uygun amaçlarla çocukların bilişsel becerilerinin desteklendiği rahatlıkla söylenebilir. Ancak derlemedeki önerilerin erken çocukluk eğitimi programlarında yürütücü işlevler becerilerine yönelik olarak daha açık amaçların yazılması ve buna uygun oyunlar, rutinler ve etkinliklerin planlanıp yürütülmesi yönünde olduğu düşünülmektedir. Bu kapsamda erken çocukluk eğitimi programında bilişsel esneklik, öz düzenleme, planlama, çalışma belleği, ketleme kontrolü, dikkat, duygusal ve davranışsal düzenleme, öz denetim, uyarıcıları düzenleme, 
düşünme, organize etme, problem çözme, karar verme ve konuşma akıc1lığı gibi becerilerin geliştirilmesine yönelik amaçların detaylı olarak planlanması ve bu amaçların gerçekleşmesini destekleyen oyunların ve etkinliklerin yerleştirilmesi İK çocukların yürütücü işlevler performansını destekleyeceği düşünülmektedir. Ayrıca bu oyunların ve etkinliklerin hem bireyselleştirilmiş eğitimlerde hem de grup eğitimlerinde İK çocuklarla çalışılması önemli bulunmaktadır.

\section{Sonuç ve Öneriler}

Sonuç olarak yürütücü işlevler ile diğer bilişsel süreçler/beceriler arasında ilişkiye dair bir yargıya varılamadığ fakat yürütücü işlevler ile işitsel yoksunluk ve dil arasında nedensellikten ziyade karşılıklılık ilişkisi olduğu söylenebilir. İK çocuklarda yürütücü işlevler ile diğer bilişsel süreçler/beceriler arasındaki ilişkiye dair bilgilere gereksinim duyulması, koklear implantlı ile işitme cihazlı çocuklar arasında ve anadili işaret dili olanlar ve işiten çocuklar arasında yürütücü işlevler performansında farklılık olmaması bu yönde daha çok araştırmaya ihtiyacın olduğunu göstermektedir. Var olan araştırmalarda nicel araştırma desenlerinin tercih edildiği görülmektedir. Bu nedenle, özellikle eğitim uygulamaları için, nitel yöntemlerle desenlenen araştırmalara ihtiyaç olduğu düşünülmektedir. İK çocukların yürütücü işlevler performansının, doğal ortamlarda konuya hâkim uzmanlar tarafından değerlendirilerek ortaya konduğu vaka araştırmaları yapılabilir. Yeni araştırmaların, İK çocuklar için erken eğitim programlarında yürütücü işlevlerin desteklenmesine ilişkin yeni stratejilerin geliştirilmesine katkı sağlayacağı düşünülmektedir. İK çocukların eğitim programları planlanırken dil gelişimiyle birlikte bilişsel gelişimin de dengeli biçimde dikkate alındığı ve desteklendiği erken eğitim programlarıyla İK çocukların yürüttücü işlevler performansının işiten akranlarına yaklaşmasının mümkün olabileceği ileri sürülebilir.

Son olarak araştırmanın belirli sınırlılıkları bulunmaktadır. Araştırmanın ilk sınılıılı̆̆ yazarların arama motorlarında ulaşabildiği araştırmalarla sınırlı olmasıdır. Bu derlemede araştırmalar, yöntemsel özellikleri (katılımcı özellikleri, araştırma desenleri, ölçme araçları), ana bulguları ve eğitim uygulamalarına yönelik önerileri bağlamında sentezlenmiştir. Eğitim alanındaki sistematik derlemeler için kalite kontrol değerlendirme aracı konusunda alanyazında yaşanan sınırlılık nedeniyle bu araştırmada da herhangi bir kalite kontrol değerlendirme aracı kullanılamamıştır. Bu bağlamda ileriki araştırmalar için kalite kontrol değerlendirme araçlarının geliştirilmesi ve araştırma bulgularının birleştirilerek istatistiksel analizlerinin yapılacağ araştırmalarının yapılması önerilebilir.

\section{Yazarların Katkı Düzeyleri}

Yazarlar araştırmanın tüm bölümlerinde eşit düzeyde görev almışlardır. 


\section{Kaynaklar}

Not: Derlemeye dahil edilen makaleler * ile gösterilmiştir.

*AuBuchon, A. M., Pisoni, D. B., \& Kronenberger, W. G. (2015). Verbal processing speed and executive functioning in long-term cochlear implant users. Journal of Speech, Language, and Hearing Research, 58(1), 151-162. https://doi.org/10.1044/2014 JSLHR-H-13-0259

Barbosa, A. C. C., Lukasova, K., Mecca, T. P., \& Macedo, E. C. (2013). Intelligence assessment of deaf students with TONI 3. Psico-USF, Bragança Paulista, 18(2), 183-192. https://doi.org/10.1590/S141382712013000200002

Barkley, R. A. (2012). Executive functions: What they are, how they work, and why they evolved. The Guilford Press.

*Beer, J., Kronenberger, W. G., Castellanos, I., Colson, B. G., Henning, S. C., \& Pisoni, D. B. (2014). Executive functioning skills in preschool-age children with cochlear implants. Journal of Speech, Language, And Hearing Research, 57(4), 1521-1534. https://doi.org/10.1044/2014 JSLHR-H-13-0054

*Beer, J., Kronenberger, W. G., \& Pisoni, D. B. (2011). Executive function in everyday life: Implications for young cochlear implant users. Cochlear Implants International, 12(1), 89-91. https://doi.org/10.1179/146701011X13001035752570

Beer, J., Pisoni, D. B., Kronenberger, W. G., \& Geers, A. E. (2010). New research findings executive functions of adolescents who use cochlear implants. The American Speech-Language-Hearing Association (ASHA) Leader, 15(15), 12-14. https://doi.org/10.1044/leader.FTR2.15152010.12

Bernier, A., Carlson, S. M., \& Whipple, N. (2010). From external regulation to self-regulation: Early parenting precursors of young children's executive functioning. Child Development, 81(1), 326-339. https://doi.org/10.1111/j.1467-8624.2009.01397.x

Berk, L. E. (2008). Infants and children: Prenatal through middle childhood (6th ed.). Allyn and Bacon.

Bharadwaj, S. V., \& Mehta, J. A. (2016). An exploratory study of visual sequential processingin children with cochlear implants. International Journal of Pediatric Otorhinolaryngology, 85(2016), 158-165. https://doi.org/10.1016/j.ijporl.2016.03.036

Bodrova, E., \& Leong, D. J. (2013). Zihnin araçları: Erken çocukluk eğitiminde Vygotsky yaklaşımı [Tools of the mind: The Vygotskian approach to early choldhood education]. (T. Güler, F. Şahin, A. Y1lmaz, \& E. Kalkan, Çev.; 2. baskı). Anı Yayıncılık. (Orijinal kitabın yayın tarihi 1996)

Braden, J. P. (2001). The clinical assessment of deaf people's cognitive abilities. In M. D. Clark, M. Marschark, \& M. Karchmer (Eds.), Context, cognition, and deafness (pp. 14-37). Gallaudet University Press.

Brown, P. M., \& Nott, P. (2005). Family-centered practice in early intervention for oral language development: Philosophy, methods, and results. In P. E. Spencer \& M. Marschark (Eds.), Advances in the spoken language development of deaf and hard-of-hearing children (pp. 136-165). Oxford University Press.

Bruder, M. B. (2010). Early childhood intervention: A promise to children and families for their future. Exceptional Children, 76(3), 339-355. https://doi.org/10.1177/001440291007600306

Carlson, S. M. (2003). Executive function in context: Development, measurement, theory, and experience. Monographs of the Society for Research in Child Development, 68(3), 138-151. https://doi.org/10.1111/j.1540-5834.2003.06803012.x

Clark, M. D. (2001). Interdisciplinary perspectives on context, cognition, and deafness: An introduction. In M. D. Clark, M. Marschark \& M. Karchmer (Eds.), Context, cognition, and deafness (pp. 1-5). Gallaudet University Press.

Cleary, M., Pisoni, D. B., \& Geers, A. E. (2001). Some measures of verbal and spatial working memory in eightand nine-year-old hearing-impaired children with cochlear implants. Ear and Hearing, 22(5), 395-411. https://doi.org/10.1097/00003446-200110000-00004 
*Daza, M. T., Phillips-Silver, J., Del Mar Ruiz-Cuadra, M., \& López-López, F. (2014). Language skills and nonverbal cognitive processes associated with reading comprehension in deaf children. Research in Developmental Disabilities, 35(12), 3526-3533. https://doi.org/10.1016/j.ridd.2014.08.030

Decker, K. B., \& Vallotton, C. D. (2016). Early intervention for children with hearing loss: Information parents receive about supporting children's language. Journal of Early Intervention, 38(3), 151-169. https://doi.org/10.1177\%2F1053815116653448

*De Villiers, P. A., \& De Villiers, J. G. (2012). Deception dissociates from false belief reasoning in deaf children: Implications for the implicit versus explicit theory of mind distinction. British Journal of Developmental Psychology, 30(1), 188-209. https://doi.org/10.1111/j.2044-835X.2011.02072.x

Doğan, M., \& Hasanoglu, G. (2016). Content analysis of memory and memory-related research studies on children with hearing loss. Educational Research and Reviews, 11(16), 1542-1559. https://doi.org/10.5897/ERR2016.2793

Edwards, L., \& Crocker, S. (2008). Psychological processes in deaf children with complex needs: An evidencebased practical guide. Jessica Kingsley Publishers.

Ertürk-Mustul, E., Turan, Z., \& Uzuner, Y. (2016). İşitme kayıplı çocuğu olan bir annenin etkileşim davranışlarının aile eğitimi bağlamında incelenmesi [Evaluation of the interactive behaviors of a mother with her child who have a hearing loss in the context of parent guidance process]. Ankara Üniversitesi Eğitim Bilimleri Fakültesi Özel Eğitim Dergisi, 17(1), 1-22. https://doi.org/10.1501/Ozlegt_0000000236

Estabrooks, W., Maclver-Lux, K., Rhoades, E. A., \& Lim, S. R. (2016). Auditory-verbal therapy: An overview. In W. Estrabrooks, K. Maclver-Lux \& E. A. Rhoades (Eds.), Auditory-verbal therapy: For young children with hearing lossand their families, and the practitioners who guide them (pp. 1-22). Plural Publishing.

*Figueras, B., Edwards, L., \& Langdon, D. (2008). Executive function and language in deaf children. Journal of Deaf Studies and Deaf Education, 13(3), 362-377. https://doi.org/10.1093/deafed/enm067

Furth, H. G., \& Pufall, P. B. (1966). Visual and auditory sequence learning in hearing-impaired children. Journal of Speech and Hearing Research, 9(3), 441-449. https://doi.org/10.1044/jshr.0903.441

Gay, L. R., Mills, G. E., \& Airasian, P. W. (2016). Educational research: Competencies for anlaysis and applications. Pearson Merrill Prentice Hall.

Geers, A., Brenner, C., \& Davidson, L. (2003). Factors associated with development of speech perception skills in children implanted by age five. Ear and Hearing, 24(1), 24-35. https://doi.org/10.1097/01.aud.0000051687.99218.0f

Glanemann, R., Reichmut, K., Matulat, P., \& Zehnhoff-Dinnesen, A. (2013). Muenster parental programme empowers in communicating with their infant with hearing loss. International Journal of Pediatric Otorhinolaryngology, 77(12), 2023-2029. https://doi.org/10.1016/j.ijporl.2013.10.001

Grove, S. K., Gray, J. R., \& Burns, N. (2015). Understanding nursing research: Building and evidence-based practice (6th ed.). Elsevier.

*Hall, M. L., Eigsti, I. M., Bortfeld, H., \& Lillo-Martin, D. (2017). Auditory deprivation does not impair executive function, but language deprivation might: Evidence from a parent-report measure in deaf native signing children. The Journal of Deaf Studies and Deaf Education, 22(1), 9-21. https://doi.org/10.1093/deafed/enw054

Hanson, V. L. (1990). Recall of order information by deaf signers: Phonetic coding in temporal order recall. Memory \& Cognition, 18(6), 604-610. https://link.springer.com/article/10.3758/BF03197103

*Hintermair, M. (2013). Executive functions and behavioral problems in deaf and hard-of-hearing students at general and special schools. Journal of Deaf studies and Deaf Education, 18(3), 344-359. https://doi.org/10.1093/deafed/ent003

Hornby, G. (Ed.). (2014). Inclusive special education: Evidence-based practices for children with special needs and disabilities. Springer. 
Howard, V. F., Williams, B., \& Lepper, C. E. (2011). Özel gereksinimi olan küçük çocuklar: Eğitimciler, aileler ve hizmet verenler için bir başlangıç [Very young children with special needs: A foundation for educators, families, and service providers]. (G. Akçamete, Çev.; 4. baskı). Nobel Yayıncılık. (Orijinal kitabın yayın tarihi 2010)

Huber, M., Kipman, U., \& Pletzer, B. (2014). Reading instead of reasoning? Predictors of arithmetic skills in children with cochlear implants. International Journal of Pediatric Otorhinolaryngology, 78(7), 11471152. https://doi.org/10.1016/j.ijporl.2014.04.038

Hughes, C., Graham, A., \& Grayson, A. (2004). Executive function in childhood: Development and disorder. In J. Oates \& A. Grayson (Eds.), Cognitive and language development in children (pp. 205-230). Open University Press.

Ingvalson, E. M., Young, N. M., \& Wong, P. C. (2014). Auditory-cognitive training improves language performance in prelingually deafened cochlear implant recipients. International Journal of Pediatric Otorhinolaryngology, 78(10), 1624-1631. https://doi.org/10.1016/j.ijporl.2014.07.009

Joint Committee on Infant Hearing. (2013). Supplement to the JCIH 2007 position statement: Principles and guidelines for early intervention after confirmation that a child is deaf or hard of hearing. Pediatrics, 131(4), 1324-1349. http://www.pediatrics.org/cgi/doi/10.1542/peds.2013-0008

Jutras, B., \& Gagné, J. (1999). Auditory sequential organization among children with and without a hearing loss. Journal of Speech, Language, and Hearing Research, 42(3), 553-567. https://doi.org/10.1044/jslhr.4203.553

Karaçam, Z. (2013). Sistematik derleme metodolojisi: Sistematik derleme hazırlamak için bir rehber [Systematic review methodology: A guide for preparation of systematic review]. Dokuz Eylül Üniversitesi Hemşirelik Fakültesi Elektronik Dergisi, 6(1), 26-33. https://dergipark.org.tr/en/download/article-file/753523

Kargın, T. (2004). Kaynaştırma: Tanımı, gelişimi ve ilkeleri [Inclusion: Definition, development and principles]. Ankara Üniversitesi Eğitim Bilimleri Fakültesi Özel Eğitim Dergisi, 5(2), 1-13. https://dergipark.org.tr/en/download/article-file/159199

Kronenberger, W. G., Pisoni, D. B., Henning, S. C., \& Colson, B. G. (2013). Executive functioning skills in longterm users of cochlear implants: A case control study. Journal of Pediatric Psychology, 38(8), 902-914. https://doi.org/10.1044/1092-4388(2012/11-0356)

Laugen, N. J., Jacobsen, K. H., Rieffe, C., \& Wichstrøm, L. (2016). Predictors of psychosocial outcomes in hardof-hearing preschool children. The Journal of Deaf Studies and Deaf Education, 21(3), 259-267. https://doi.org/10.1093/deafed/enw005

Leigh, G. (2008). Changing parameters in deafness and deaf education: Greater opportunity but continuing diversity. In M. Marschark \& P. C. Hauser (Eds.), Deaf cognition: Foundations and outcomes (pp. 2451). Oxford University Press.

Ling, A. H. (1975). Memory for verbal and nonverbal auditory sequences in hearing-impaired and normal-hearing children. Ear and Hearing, 1(1), 37-45. https://journals.lww.com/earhearing/Abstract/1975/07000/MEMORY_FOR_VERBAL_AND_NONVERBAL_AUDITORY_SEQU ENCES.8.aspx

Lyxell, B., Wass, M., Sahlén, B., Samuelsson, C., Asker-Árnason, L., Ibertsson, T., Maki-Torkko, E., Larsby, B., \& Hällgren, M. (2009). Cognitive development, reading and prosodic skills in children with cochlear implants. Scandinavian Journal of Psychology, 50(5), 463-474. https://doi.org/10.1111/j.14679450.2009.00754.x

Maller, S. J. (2003). Intellectual assessment of deaf people: A critical review of core concepts and issues. In M. Marschark, \& P. E. Spencer (Eds.), The Oxford handbook of deaf studies, language, and education (pp. 464-477). Oxford University Press.

Marschark, M. (2001). Context, cognition, and deafness: Planning the research agenda. In M. D. Clark, M. Marschark \& M. Karchmer (Eds.), Context, cognition, and deafness (pp. 179-198). Gallaudet University Press. 
Marschark, M. (2003). Cognitive functioning in deaf adults and children. In M. Marschark \& P. E. Spencer (Eds.), Deaf studies, language and education (pp. 464-477). Oxford University Press.

Marschark, M. (2006). Intellectual functioning of deaf adults and children: Answers and questions. European Journal of Cognitive Psychology, 18(1), 70-89. https://doi.org/10.1080/09541440500216028

Marschark, M., \& Hauser, P. C. (2008). Cognitive underpinnings of learning by deaf and hard-of-hearing students: Differences, diversity, and directions. In M. Marschark \& P. C. Hauser (Eds.), Deaf cognition: Foundations and outcomes (pp. 3-23). Oxford University Press.

Marschark, M., \& Knoors, H. (2012). Educating deaf children: Language, cognition, and learning. Deafness \& Education International, 14(3), 136-160. https://doi.org/10.1179/1557069X12Y.0000000010

Marschark, M., \& Mayer, T. S. (1998). Mental representation and memory in deaf adults and children. In M. Marschark \& D. Clark (Eds.), Psychological perspectives on deafness (pp. 53-77). Lawrence Erlbaum Associates, Inc.

May-Mederake, B. (2012). Early intervention and assessment of speech and language development in young children with cochlear implants. International Journal Paediatric Otorhinolaryngology, 76(7), 1-8. https://doi.org/10.1016/j.ijporl.2012.02.051

*Meristo, M., \& Hjelmquist, E. (2009). Executive functions and theory-of-mind among deaf children: Different routes to understanding other minds? Journal of Cognition and Development, 10(1-2), 67-91. https://doi.org/10.1080/15248370902966552

Moeller, M. P., Carr, G., Seaver, L., Stredler-Brown, A., \& Holzinger, D. (2013). Best practicesin family-centered early intervention for children who are deaf or hard of hearing: An international consensus statement. The Journal of Deaf Studies and Deaf Education, 18(4), 429-445. https://doi.org/10.1016/j.ijporl.2012.02.051

*Nazarzadeh, F., Fazlali, N., Mozaffari, N., \& Mashhadi, A. (2014). The relationship of theory of mind and executive functions in normal, deaf and cochlear-implanted children. Bimonthly Audiology-Tehran University of Medical Sciences, 23(3), 82-89. https://aud.tums.ac.ir/article-1-5002-en.pdf

Netten, A. P., Rieffe, C., Theunissen, S. C., Soede, W., Dirks, E., Korver, A. M., Konings, S., Oudesluys-Murphy, A. M., Dekker, F. W., Frijns, J., \& DECIBEL Collaborative Study Group. (2015). Early identification: Language skills and social functioning in deaf and hard of hearing preschool children. International $\begin{array}{llll}\text { Journal of Pediatric } & \text { Otorhinolaryngology, }\end{array}$ https://doi.org/10.1016/j.ijporl.2015.10.008

Niparko, J. K., Tobey, E. A., Thal, D. J., Eisenberg, L. S., Wang, N. Y., Quittner, A. L., Fink, N. E., \& CDaCI Investigative Team. (2010). Spoken language development in children following cochlear implantation. JAMA, 303(15), 1498-1506. https://doi.org/10.1001/jama.2010.451

Norman, D. A., \& Shallice, T. (1986). Attention to action: Willed and automatic control of behavior. In R. J. Davidson, G. E. Schwartz \& D. Shapiro (Eds.), Consciousness and self-regulation: Advances in research and theory (pp. 1-18). Plenum. http://www.dtic.mil/dtic/tr/fulltext/u2/a094713.pdf

*Oberg, E., \& Lukomski, J. (2011). Executive functioning and the impact of a hearing loss: Performance-based measures and the Behavior Rating Inventory of Executive Function (BRIEF). Child Neuropsychology, 17(6), 521-545. https://doi.org/10.1080/09297049.2011.555760

Phillips, J., Wiley, S., Barnard, H., \& Meinzen-Derr, J. (2014). Comparison of two nonverbal intelligence tests among children who are deaf or hard-of-hearing. Research in Developmental Disabilities, 35(2), 463 471. https://doi.org/10.1016/j.ridd.2013.11.020

Pisoni, D. B., \& Cleary, M. (2004). Learning, memory, and cognitive processes in deaf children following cochlear implantation. In F. G. Zeng, A. N. Popper \& R. Fay (Eds.), Cochlear implants: Auditory prostheses and electric hearing (pp. 377-426). Springer.

Pisoni, D. B., Conway, C. M., Kronenberger, W. G., Horn, D. L., Karpicke, J., \& Henning, S. C. (2008). Efficacy and effectiveness of children of cochlear implants in deaf children. In M. Marschark \& P. C. Hauser (Eds.), Deaf cognition: Foundations and outcomes (pp. 52-101). Oxford University Press. 
*Remine, M. D., Care, E., \& Brown, P. M. (2008). Language ability and verbal and nonverbal executive functioning in deaf students communicating in spoken English. Journal of Deaf Studies and Deaf Education, 13(4), 531-545. https://doi.org/10.1093/deafed/enn010

Santrock, J. (2011). Child development (13th ed.). McGraw-Hill Companies, Inc.

Santrock, J. (2013). Life-span development (14th ed.). McGraw-Hill Companies, Inc.

Shand, M. A. (1982). Sign-based short-term coding of American Sign Language signs and printed English words by congenitally deaf signers. Cognitive Psychology, 14(1), 1-12. https://doi.org/10.1016/00100285(82)90002-0

Sugaya, A., Fukushima., K., Kasai, N., Kataoka, Y., Maeda, Y., Nagayasu, R., Toida, N., Ohmori, S., Fujiyoshi, A., Taguchi, T., Omichi, R., \& Nishizaki, K. (2015). Impact of early intervention on comprehensive language and academic achievement in Japanese hearing impaired children with cochlear implants. International Journal of Pediatric Otorhinolaryngoly, 79(12), 2142-2146. https://doi.org/10.1016/j.ijporl.2015.09.036

*Surowiecki, V. N., Maruff, P., Busby, P. A., Sarant, J., Blamey, P. J., \& Clark, G. M. (2002). Cognitive processing in children using cochlear implants: The relationship between visual memory, attention, and executive functions and developing language skills. Annals of Otology, Rhinology \& Laryngology, 111(5_suppl), 119-126. https://doi.org/10.1177\%2F00034894021110S524

*Şipal, R. F., \& Bayhan, P. (2010). Assessing the link between executive functions and aggressive behaviours of children who are deaf: Impact of early special education. Electronic Journal of Research in Educational Psychology, $8(3)$, 991-1014. http://repositorio.ual.es/bitstream/handle/10835/908/Art_22_472.pdf?sequence=1

Todman, J., \& Seedhouse, E. (1994). Visual-action code processing by deaf and hearing children. Language and Cognitive Processes, 9(2), 129-141. https://doi.org/10.1080/01690969408402113

Turan, Z. (2019). Supervision on early intervision practices for teachers of the deaf. Educational Research and Reviews, 14(11), 388-396. https://doi.org/10.5897/ERR2019.3717

Turan, Z., Koca, A., \& Uzuner, Y. (2019). İşitme kayıplı çocuğu olan bir annenin aile eğitimi sürecinin incelenmesi [Evaluation of the early intervention process of the mother of a child with hearing loss]. Ankara Üniversitesi Eğitim Bilimleri Fakültesi Özel Ĕgitim Dergisi, 20(1), 93-117. https://doi.org/10.21565/ozelegitimdergisi.417177

Vygotsky, L. S. (1998). Düşünce ve dil [Thought and language]. (S. Koray, Çev.; 2. bask1). Toplumsal Dönüşüm. (Orijinal kitabın yayın tarihi 1954)

*Woolfe, T., Want, S. C., \& Siegal, M. (2002). Signposts to development: Theory of mind in deaf children. Child Development, 73(3), 768-778. https://doi.org/10.1111/1467-8624.00437 


\section{Ankara University Faculty of Educational Sciences Journal of Special Education}

2022, 23(1), 165-189

\section{REVIEW}

Recieved Date: 18.05 .20

Accepted Date: 27.01.21

OnlineFirst: 31.01 .21

\title{
Systematic Review of Studies on Executive Functions in Children with Hearing Loss*
}

\author{
Emel Ertürk-Mustul iD 1
}

\author{
Murat Doğan $(\mathrm{D} / 2$
}

\begin{abstract}
Introduction: The aim of this study is to provide a general perspective on the relationship between executive functions and other cognitive processes/skills in children with hearing loss (HL), and performance of these children by reviewing studies focusing on executive functions.
\end{abstract}

Method: 15 studies on executive functions in children with HL were reviewed.

Findings: The findings indicated that (a) there was an interdependence between executive functions and language, and in terms of executive functions (b) children with HL experienced more difficulties compared to hearing peers, (c) there was no difference between children with cochlear implants and hearing aids, and between native sign language users and hearing children, (d) children with cochlear implants in the inclusion were more successful than those at school for the deaf, and (e) cognitive processes in early education programs should be supported in a balanced manner with language.

Discussion: The finding that children with HL lag behind hearing peers is consistent with the findings of studies examining other cognitive processes. No definitive conclusion was reached regarding the relationship between executive functions and other cognitive processes/skills, although interdependence was found between executive functions and language.

Conclusion and Implications: Findings indicated that further research were needed on the topic and new research may contribute to early education programs. It can be argued that through early education programs, supporting cognitive as well as language development in a balanced manner may help children with HL close the gap with their hearing peers in executive function.

Keywords: Children with hearing loss, cochlear implant, cognitive processes/skills, executive functions, early education programs.

\footnotetext{
*This study was presented as an oral presentation at the $5^{\text {th }}$ International Eurasian Education Research Congress held in Antalya between 2-5 May 2018.

${ }^{1}$ Corresponded Author: Res., Asisst. Anadolu University, E-mail: emelerturk@anadolu.edu.tr, https://orcid.org/0000-00016641-6146

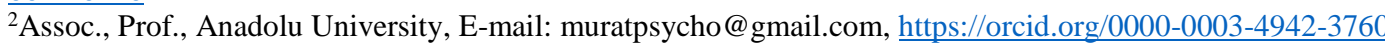


To cite: Ertürk-Mustul, E., \& Doğan, M. (2022). Systematic review of studies on executive functions in children with hearing loss. Ankara University Faculty of Educational Sciences Journal of Special Education, 23(1), 165-189. https://doi.org/10.21565/ozelegitimdergisi.739073

\section{Introduction}

Academic interest in cognitive processes in children with hearing loss (HL) has increased significantly in years for various reasons. There has been an increasing interest to identify the relationship between cognitive characteristics and academic performance among children with HL and to identify the cognitive factors affecting their language and speaking skills (Braden, 2001; Clark, 2001; Marschark, 2001). Concerning educational practices, this interest is motivated also by the need for cognitive evaluations related to early intervention practices and the educational settings where a child should be placed (Edwards \& Crocker, 2008). In the early 2000s, the idea of integrating applied and basic research in studies of children with HL gave additional momentum to cognition studies (Clark, 2001; Marschark, 2001). Among the studies of cognitive processes in this group, those on intelligence were particularly prominent, in which it was shown that children with HL differed from their hearing peers in skills requiring abstract thinking such as sense of humor and the use of metaphors (Barbosa et al., 2013; Marschark, 2003, 2006; Phillips et al., 2014). These were followed by the studies of memory among which Doğan and Hasanoğlu (2016) made a review of studies published between 2000 and 2015 on memory and memoryrelated processes to identify the general methodology and topics. They found that a significant proportion of the studies had causal-comparative and correlational research designs. They found that memory was mostly studied in children with cochlear implants, and a large majority of these children communicated verbally; a positive relationship existed between memory, language and literacy; the educational setting was predominantly an inclusive classroom; and almost all studies examined short-term memory and working memory. Through the advances in hearing technologies and early education there has been a growing interest in the factors affecting language development, leading to studies of executive function skills related to knowledge processing from the 2000s onwards (Figueras et al., 2008; Pisoni et al., 2011; Surowiecki et al., 2002; Woolfe et al., 2002).

\section{Definition and Content of Executive Functions}

Similar to all cognitive skills, executive function skills start developing in the first years of life and continue to develop depending on neurological development (Beer et al., 2014; Beer et al., 2010; Hughes et al., 2004). Executive functions are the cognitive processes involved in planning a task, organizing planned/purposive behavior, and initiating, maintaining and completing the planned behavior (Beer et al., 2014; Beer et al., 2010; Hall et al., 2017). Adults support children's skills in the context of their interactions, helping children to develop executive function skills (Bernier et al., 2010; Bodrova \& Leong, 1996, 2013). Thus, as their executive functions develop, children gain a greater ability to learn and develop new skills and spend more time on the particular tasks they initiate. Children become more flexible and capable of organizing their thoughts and behaviors. They develop stronger skills in dealing with more complex planning, organizing and decision-making processes (Hughes et al., 2004). Executive functions include the ability to pay attention and listen to the teacher in class along with starting and completing homework. In adults, such functions include the ability to deal with stressful situations and resist unhealthy food (Norman \& Shallice, 1986).

\section{Executive Functions in Children with HL}

The development of executive function skills starting at an early age is reported to be affected by hearing loss (Geers et al., 2003). It is suggested that a relationship exists between executive functions and language that are based on mutual action and reaction processes in that executive function skills include some of the skills required also for speech, including self-regulation, verbal mediation, working memory, sequential processing strategies, and the tools and experiences used when performing tasks (language, phonological awareness). Subsequently, it is argued that executive functions are closely related to language and influence language development (Beer et al., 2011; Kronenberger et al., 2013). Most studies related to executive functions in children with HL focus on those with cochlear implants, which can contribute to the improvement of language skills (e.g., Aubuchon et al., 2014; Beer et al., 2014; Kronenberger et al., 2013). Performance levels may vary in such cases. This can be attributed to such variables as individual differences, family participation, early education and method of communication among others. Regarding this issue, the question "Why are some children with cochlear implants able to catch up with their hearing peers whereas others lag behind?" has arised. Learning about the roles of the individual cognitive processes may help explain why some children with cochlear implants lag behind their hearing peers (Pisoni et al., 2008; Pisoni \& Cleary, 2004). In this context, there is a limited number of international researches on executive functions in children with HL (e.g., Figueras et al., 2008; Surowiecki et al., 
2002) while there is only one research in the national literature (Şipal \& Bayhan, 2010). For this reason, it is thought that reaching a synthesis by systematically compiling the findings in the literature regarding the relationship between executive functions and other cognitive processes/skills (especially language) will contribute to the literature. It is believed that the findings will be guiding researchers and practitioners working in the field in terms of planning their educational programs.

There have been many studies to date examining the relationship between language and such processes as intelligence, memory, attention, reading skills and phonological awareness, but few have addressed the relationship between executive functions and other cognitive processes/skills. The present study is motivated by the assumption that a relationship exists between executive functions and language in children with HL along with the desire to understand the relationship between executive functions and other cognitive processes/skills. To this end, it is aimed to provide a general perspective on the relationship between executive functions and other cognitive processes/skills in children with HL, and performance of these children by reviewing studies focusing on executive functions. Answers were sought to the following questions:

1. What are the methodological features (participant characteristics, research designs, measurement tools) of the studies?

2. What are the main findings of the studies?

3. What do the studies recommend for educational practices?

\section{Method}

This study adopts a systematic review methodology where field experts make a comprehensive review of all published studies on a specific theme, making a systematic and comprehensive synthesis of the findings of studies identified as a result of inclusion and exclusion criteria (Grove et al., 2015; Karaçam, 2013).

\section{Search Strategy}

The searches carried out for this study had no time limit. The first stage of the literature search involved searches for various combinations of such key words in English as "executive functions", "children with HL", "deaf", "hard of hearing", "hearing impairment", "cochlear implant" and Turkish versions of these words in the Ebscohost, Eric, Google Schoolar, OECD iLibrary, Sage, ScienceDirect, SpringerLink, Scopus, Taylor \& Francis and Web of Science databases. The second stage of the search was based on the references of the studies identified in the first stage.

\section{Review Process}

In this study, 47 studies were identified in the review. A review of the titles and abstracts of the studies identified 10 replicates which were then removed. After examining the full texts of the studies, 9 were found to be indirectly related to the topic and removed. To be included in the review, the studies had to be: empirical studies based on data; published in a peer-reviewed journal; conducted with children with HL aged $\leq 18$; and focused directly on executive functions or the relationship between executive functions and other processes/skills. Following the application of these criteria, a further eight studies were removed as their participants were aged $>18$, three informative studies were removed, one validity and reliability study was removed, and one thesis study conducted in another country was removed. Consequently, 15 empirical studies were included. In order to ensure the reliability of the study, the authors examined 15 studies together and coded by providing consensus.

\section{Findings and Discussion}

This study aims to provide a general overview of the relationship between executive functions and other cognitive processes/skills in children with HL, and performance of these children. Following the research questions, the findings are presented and discussed in separate sections including the methodological features of the studies, the main findings and the recommended educational practices.

\section{Methodological Features of the Studies}

\section{Participant Characteristics}

The participants $(n=832)$ were aged between 3 and 18 years. It was difficult to create homogeneous groups in terms of age, gender, level and type of HL, method of communication, and educational setting as the 
studies lacked sufficient numbers of children with HL. In $47 \%$ of the studies, the norm group was made up of hearing children based on the philosophy of inclusion, requiring all students to receive education in the same educational setting (Braden, 2001; Hornby, 2014; Leigh, 2008).

Of the total, $6 \%$ of the participants had additional disabilities, the majority of which were intellectual disability; 35\% used cochlear implants; $13 \%$ used hearing aids; $6 \%$ had used hearing aids in the past; $45 \%$ didn't specify the type of hearing technology used; $61 \%$ used verbal communication; $25 \%$ used sign language; $11 \%$ used the total communication method; $48 \%$ attended schools for the deaf; $31 \%$ received education in inclusive settings; and $12 \%$ received early education. Only some of the studies provided detailed information about the audiological and educational characteristics of children with HL although these are characteristics that could affect cognitive and other development. This was probably not reported due to the insufficiency of past records. The audiological and educational findings indicated that it would be very difficult to comply with the universal standards set by the Joint Committee on Infant Hearing (JCIH, 2013). It is recommended that children with HL be diagnosed within maximum three months, be fitted with hearing aids within maximum six months and be enrolled in early education programs. Qualified early intervention programmes are necessary to prepare children for the least restrictive educational settings. Inclusive classrooms are considered to be the least restrictive settings and schools for the deaf the most restrictive (Kargin, 2004). Given that a significant proportion of the participants used cochlear implants and that the most preferred verbal communication method, the finding that almost half of all participants received education in the most restrictive settings was unexpected. Based on JCIH's (2013) universal standards and recommendations in literature, it could be argued that the children $(n=832)$ who participated in the reviewed studies were not offered sufficient audiological guidance and educational opportunities. This is albeit that executive functions start developing at an early age and continue to develop well into adulthood (Beer et al., 2014; Beer et al., 2010; Hughes et al., 2004). Early education which is known to support all areas of development in children with HL would support also executive function skills. If the necessary conditions aren't met in audiological and early education, having high expectations of cognitive skills in general and executive functions in particular may lead to disappointment. In conclusion, variations in the audiological experiences, preferred communication methods, education histories and educational settings of children with HL as well as in the hearing technologies used can lead to difficulties in general and individualized education programs, teachers, teacher training institutions and educational research (Leigh, 2008).

\section{Research Design}

All studies on this topic utilized quantitative methods. Using Gay et al. (2016) classification, the most common design was causal-comparative (67\%) followed by correlational $(27 \%)$ and descriptive $(7 \%)$ in compliance with the nature of designs. Causal-comparative studies focus on a preexisting difference in a natural setting, giving rise to a variable that is impossible to manipulate. As HL was not influenced by the researcher and was impossible to manipulate, the causal-comparative design was the most common design in these studies. However, correlational studies examine the relationship between changes in two variables but do not allow cause and effect conclusions to be made (Gay et al., 2016). As mentioned in the introduction, executive functions are assumed to be related to language. This study design is used due to the need to understand the relationship between executive functions and other cognitive processes/skills. The content analysis carried out by Doğan and Hasanoğlu (2016) also found that most studies had a causal-comparative or correlational research design, giving an idea of the overall methodological tendency in studies of cognitive processes among children with HL.

\section{Assessment Tools}

Various assessment tools have been used to measure executive functions. Of the 19 different assessment tools, $53 \%$ were tasks; $26 \%$ were standard tests, $16 \%$ were test batteries and $5 \%$ were scales. In $60 \%$ of the studies, the assessment tool was administered directly by an expert and was based on parents/teacher responses in $33 \%$ of the studies, while in 7\%, experts both administered the assessment tool directly to the parents and evaluated the responses. Executive functions are difficult to assess in that they contain numerous components/skills. When assessing executive functions, it is recommended to use of multiple and standardized assessment tools to ensure assessment reliability. The direct administration of assessment tools by experts was the most common approach. This showed that direct assessment was the preferred method in these studies (Barkley, 2012; Hall et al., 2017).

\section{Main Findings of the Studies}

The main findings of the studies are organized under three themes: (i) The relationship between executive functions and other cognitive processes/skills, (ii) the performance of executive functions and comparative results 
(hearing children, children with HL, those with cochlear implants, those with/without sign language as their mother tongue), and (iii) the processes/skills/factors that affect or are affected by executive functions.

\section{The Relationship between Executive Functions and Other Cognitive Processes/Skills}

Of the total studies, $60 \%$ reported on whether or not executive functions were related with other cognitive processes/skills. Executive functions were found to be related to language (language and communication) in $27 \%$ of the studies, to reading in 7\%, to memory (perceptual encoding speed) in $7 \%$ and to behavioral problems in $7 \%$. Interestingly, executive functions were found to be unrelated to language (language, speech recognition) in 27\% of the studies, to memory (verbal rehearsal speed) in 7\%, to reading (vocabulary) in $7 \%$ and to theory of mind in $7 \%$ of the studies.

The assumption in literature that a two-way relationship existed between executive functions and language was a main motivating factor behind the present study (Beer et al., 2014; Hall et al., 2017). Therefore, it was unexpected to find that an equal number of studies found executive functions to be related and unrelated to language. Behavioral problems, memory and reading were reported in an equal number of studies to be related to executive functions, whereas reading, memory and theory of mind were the processes again reported by equal numbers of studies to be unrelated to executive functions. As such, the main findings fail to provide any substantial new information on the relationship between executive functions and other cognitive processes/skills. This can be attributed to the small number of studies reviewed and the relatively new arrival of the topic in literature. However, executive functions are found to be effective in the development of speaking skills in that they provide the tools and experiences that are used to complete such tasks as self-regulation, verbal mediation, working memory and sequential processing (Beer et al., 2011; Kronenberger et al., 2013).

\section{Executive Function Performance of Children with HL and Comparative Results}

Of all the studies analyzed, $67 \%$ reported on the executive function performance of children with HL and presented comparative results. Comparisons were made between hearing children, those with HL, those with cochlear implants, those with hearing aids, and those with sign language as their mother tongue. Furthermore, $40 \%$ of the studies reported that children with cochlear implants and hearing aids experienced greater difficulties with executive functions than their hearing peers. That said, $13 \%$ of the studies reported no difference between children with cochlear implants and those with hearing aids concerning executive function performance and $13 \%$ reported no differences between children with sign language as their mother tongue and hearing children. Among those with cochlear implants, those attending inclusive classrooms were reported to be more successful than those attending schools for the deaf $(7 \%)$ while those with genetic HL were reported to be more successful in executive functions $(7 \%)$.

The finding that children with HL (wearing cochlear implants or hearing aids) lag behind their hearing peers is consistent with the findings of studies examining other cognitive processes (Bharadwaj \& Mehta, 2016; Huber et al., 2014; Lyxell et al., 2009). The similar performance of children using cochlear implants and hearing aids can be attributed to variables such as age at diagnosis, age of first cochlear implant, duration of use, early education, family participation and current educational setting. However, the studies lack complete information on these variables which require information about the past. Cochlear implants obviously cannot replace hearing, although children who start using cochlear implants before the age of two and are supported with qualified early education are known to make significant progress in language and cognitive function and social-emotional development (Ingvalson et al., 2014; Laugen et al., 2016; May-Mederake, 2012; Netten et al., 2015; Sugaya et al., 2015).

In a study comparing children whose mother tongue was sign language and hearing children, Hall et al. (2017) found that language deprivation at an early age was an important determinant of executive function performance. Their findings showed that children with sign language as their mother tongue (who had parents with HL and who adopted sign language from birth) were no different to their hearing peers, but were still at risk in inhibition and working memory tasks. As such, auditory deprivation coupled with language deprivation at an early age is concluded to lead to difficulties in executive functions. In conclusion, current knowledge on the relationship between executive functions and language indicates interdependence rather than a one-way cause and effect relationship.

\section{Processes/Skills/Factors that Affect or are Affected by Executive Functions}


Some $33 \%$ of the studies reported on the processes/skills/factors that affected or were affected by executive functions, with theory of mind (13\%), early education (7\%), language (7\%) and gender (7\%) reported to affect executive functions respectively. One study $(7 \%)$ reported that executive functions didn't explain theory of mind. It was reported further that difficulties with executive functions could be identified in the pre-school period $(7 \%)$. Identifying the factors that affect executive functions and the processes/skills associated with executive functions in children with cochlear implants can help aid in answering the question, "Why are some children with cochlear implants able to catch up with their hearing peers whereas others lag behind? " Identifying the factors that affect executive functions and the processes/skills associated with executive functions would help in the development of new recommendations for early diagnosis, the use of hearing aids and education (Niparko et al., 2010).

\section{Recommendations Offered by Studies for Educational Practices}

Only $40 \%$ of the studies made recommendations for educational practices. The recommendations provided for the development of executive functions include coupling early diagnosis with early education and family involvement, obtaining detailed information about the etiology of HL and placement in an educational setting appropriate for the preferred method of communication. Vygotsky's theory is considered to be supportive of executive functions in that it is recommended for use in early education programs. This can be explained with reference to Vygotsky's theory of zone of proximal development, according to which children have two developmental levels: The skills that come from birth and things children can do on their own, and things children can do with help. The gap between these two levels of skills is called the zone of proximal development. The second point is scaffolding which refers to the interaction with environment/support provided by an adult to aid the child in successfully achieving their learning goals (Vygotsky, 1954; 1988). Early education programs designed with these characteristics would support all development areas and executive functions. For the early childhood education of children with HL between the ages of 0-3, literature recommends family-centered practices that set goals for each area of development (hearing, speech production, communication, language [receptive and expressive], and cognitive development), with the aim of helping children move to the next level of development from their current level. To this end, they feature games, daily routines and activities (music, early literacy, art, etc.) that serve as efficient learning environments for children aged 0-3 (Brown \& Nott, 2005; Decker \& Vallaton, 2016; Ertürk-Mustul et al., 2016; Glaneman et al., 2013; Moeller et al., 2013; Turan, 2019; Turan et al., 2019). Alternatively, early childhood education programs for those aged 3-6 use free play, early literacy activities, math preparation, science and nature, and music and art activities to support all areas of child development with developmental goals. It can thus be argued that appropriate goals integrated with games, routines and activities in early childhood education programs would support children's cognitive skills. However, the recommendations made in the reviewed studies focus mostly on clarifying goals regarding executive function skills in early childhood education programs as well as planning and conducting games, routines and activities to this end. In this context, the executive function performance of children with HL would be supported if early childhood education programs included the detailed planning of goals regarding the development of skills such as cognitive flexibility, self-regulation, planning, working memory, inhibition control, attention, emotional and behavioral regulation, self-control, stimulus regulation, thinking, organizing, problem-solving, decision-making and fluent speech and activities supporting the achievement of these goals. Moreover, it is important that these activities be conducted with children with HL both in individualized and in group lessons.

\section{Conclusion and Implications}

No definitive conclusion was reached regarding the relationship between executive functions and other cognitive processes/skills, although interdependence rather than a one-way cause and effect relationship was found between executive functions, auditory deprivation and language. The need for more information about the relationship between executive functions and other cognitive processes/skills in children with HL, and the similar levels of executive function performance reported for children with cochlear implants and those with hearing aids indicated that further studies were needed on these topics. Existing studies exclusively preferred quantitative research designs. Therefore, there is a need for studies also with qualitative research designs especially for educational practices. Case studies may be conducted in which area experts assess and explain the executive function performance of children with $\mathrm{HL}$ in natural settings. Future studies may contribute to the development of new strategies in support of executive functions in early education programs for children with HL. When planning early education programs for such children, taking into account and supporting cognitive as well as language development in a balanced manner may help children with HL close the gap with their hearing peers in executive function performance. 
Finally, there are certain limitations in this study. The first limitation is that it is limited to the research that authors can access in search engines. In this review, the studies were synthesized in the context of methodological features (participant characteristics, research patterns, measurement tools), main findings and recommendations for educational practices. Due to the limitation on the quality control assessment tool for systematic reviews in the field of education, no quality control assessment tool was used in this study. In this context, it can be suggested to develop quality control assessment tools and conduct meta-analysis. 